Global analysis of the eukaryotic pathways and networks regulated by Salmonella typhimurium in mouse intestinal infection in vivo

Liu et al. 


\title{
Global analysis of the eukaryotic pathways and networks regulated by Salmonella typhimurium in mouse intestinal infection in vivo
}

Xingyin Liu', Rong Lu', Yinglin Xia ${ }^{2}$, Jun Sun ${ }^{1,3,4^{*}}$

\begin{abstract}
Background: Acute enteritis caused by Salmonella is a public health concern. Salmonella infection is also known to increase the risk of inflammatory bowel diseases and cancer. Therefore, it is important to understand how Salmonella works in targeting eukaryotic pathways in intestinal infection. However, the global physiological function of Salmonella typhimurium in intestinal mucosa in vivo is unclear. In this study, a whole genome approach combined with bioinformatics assays was used to investigate the in vivo genetic responses of the mouse colon to Salmonella. We focused on the intestinal responses in the early stage (8 hours) and late stage (4 days) after Salmonella infection.

Results: Of the 28,000 genes represented on the array, our analysis of mRNA expression in mouse colon mucosa showed that a total of 856 genes were expressed differentially at 8 hours post-infection. At 4 days post-infection, a total of 7558 genes were expressed differentially. 23 differentially expressed genes from the microarray data was further examined by real-time PCR. Ingenuity Pathways Analysis identified that the most significant pathway associated with the differentially expressed genes in 8 hours post-infection is oxidative phosphorylation, which targets the mitochondria. At the late stage of infection, a series of pathways associated with immune and inflammatory response, proliferation, and apoptosis were identified, whereas the oxidative phosphorylation was shut off. Histology analysis confirmed the biological role of Salmonella, which induced a physiological state of inflammation and proliferation in the colon mucosa through the regulation of multiple signaling pathways. Most of the metabolism-related pathways were targeted by down-regulated genes, and a general repression process of metabolic pathways was observed. Network analysis supported IFN- $\gamma$ and TNF- $\alpha$ function as mediators of the immune/inflammatory response for host defense against pathogen.

Conclusion: Our study provides novel genome-wide transcriptional profiling data on the mouse colon mucosa's response to the Salmonella typhimurium infection. Building the pathways and networks of interactions between these genes help us to understand the complex interplay in the mice colon during Salmonella infection, and further provide new insights into the molecular cascade, which is mobilized to combat Salmonella-associated colon infection in vivo.
\end{abstract}

\section{Background}

Salmonella is a leading cause of gastrointestinal disease worldwide [1]. The overall estimated 2-4 million cases of Salmonella-induced gastroenteritis constitute a significant economic loss of productive work time, reported to exceed $\$ 2$ billion annually [2-4]. Salmonella infection can

\footnotetext{
* Correspondence: jun_sun@urmc.rochester.edu

'Department of Medicine, Gastroenterology \& Hepatology Division,

University of Rochester, 601 Elmwood Avenue, Rochester, NY 14642, USA

Full list of author information is available at the end of the article
}

appear as enteric fever, gastroenteritis, bacteremia, or extra intestinal focal infection. Central to $S$. typhimurium pathogenesis is its ability to induce intestinal inflammation [5]. Beyond the public health problem caused by Salmonella, recent studies further have demonstrated that Salmonella infection increases the risk of developing inflammatory bowel diseases (IBDs) [6]. Moreover, Salmonella infection increases the risk of other gastrointestinal (GI) diseases, including chronic inflammation and gallbladder cancer [6,7]. Therefore, it is important to

\section{Biomed Central}

(c) 2010 Liu et al; licensee BioMed Central Ltd. This is an Open Access article distributed under the terms of the Creative Commons Attribution License (http://creativecommons.org/licenses/by/2.0), which permits unrestricted use, distribution, and reproduction in any medium, provided the original work is properly cited. 
understand which pathway Salmonella target that may potentially contribute to chronic inflammation and tumorigenesis.

Increasing evidence links some Salmonella species to carcinogenesis, whereas others appear promising in the diagnosis, prevention, or treatment of cancers [8]. Salmonella and its derivatives prefer solid tumors over normal tissue in animal models $[9,10]$. Using Salmonella DNA or plasmids to cancer therapy is a very active field. Alive, mutated, non-invasive Salmonella has been used as a vector to specifically target cancer cells [11]. It may be controversial if Salmonella could contribute to intestinal inflammation and cancer. Hence, it is necessary to understand the global facets of Salmonella in the intestine using animal models.

Gene expression array technology is a powerful tool in expanding the understanding of host-pathogen interactions. Although many genes that respond to Salmonella infection have been identified in previous genomics research [12-15], the majority of such studies generally result in the identification of hundreds of genes that are involved in many different biological processes and pathways. The mouse model is widely used to study the mechanisms of systemic salmonellosis [16,17]. A number of reports have described host transcriptional responses to bacterial infection using microarrays [5,18-20]. The intestinal epithelial cells are constitutively exposed to commensal flora and pathogenic bacteria, and they play barrier, structural, and host defense roles [21-31]. The global physiological function and pathway analysis of Salmonella on intestinal mouse mucosa is unclear. We lack the knowledge of the most affected gene networks and pathways in response to Salmonella infection in mouse colon mucosa in vivo.

In this study, we focused on the intestinal responses at the early phase ( 8 hours) and the late phase ( 4 days) after Salmonella infection. The histologic assay of intestine indicated that 8 hours is the early stage of the Salmonella infection and 4 days is the late stage of infection [17]. Hence, we chose these two time courses in the current study. We used the Salmonella typhimurium wild-type SL1344 because it is a mouse-virulent strain and well-documented in in vitro and in vivo studies [17]. A whole genome approach combined with bioinformatics assays was used to dissect the genetic responses of the mouse colon to Salmonella in vivo.

\section{Methods}

\section{Bacterial strains and growth condition}

Salmonella typhimurium wild-type strain SL1344 (WT) was used in this study (provided by Dr. Jorge Galan at the Yale University) [32]. Non-agitated microaerophilic bacterial cultures were prepared by inoculating $10 \mathrm{ml}$ of Luria-Bertani broth with $0.01 \mathrm{ml}$ of a stationary phase culture followed by overnight incubation $(\sim 18 \mathrm{~h})$ at $37^{\circ} \mathrm{C}$ as previously described [33].

\section{Streptomycin pre-treated mouse model}

Animal experiments were performed using specificpathogen-free female C57BL/6 mice (Taconic, Hudson, NY, USA) that were 6-7 weeks old. The protocol was approved by the University of Rochester University Committee on Animal Resources (UCAR). Water and food were withdrawn 4 hours before oral gavage with $7.5 \mathrm{mg} /$ mouse of streptomycin. Afterwards, animals were supplied with water and food ad libitum. Twenty hours after streptomycin treatment, water and food were withdrawn again for 4 hours before the mice were infected with $1 \times 10^{7}$ CFU of S. Typhimurium $(100 \mu \mathrm{l}$ suspension in HBSS) or treated with sterile HBSS (control) by oral gavage as previously described [34]. At 8 hours and 4 days after infection, mice were sacrificed and tissue samples from the intestinal tracts were removed for analysis, as previously described [34].

\section{Sample RNA preparation}

Mice were sacrificed at 8 hours and 4 days after Salmonella infection, and tissue samples from the intestinal colon mucosa were removed. Total RNAs were isolated using TRIzol reagent (Invitrogen, Carlsbad, CA, USA) following the manufacturer's protocol, followed by oncolumn digestion of DNA using the RNeasy Mini Kit (Qiagen, Valencia, CA, USA). RNA quantity and quality were assessed with a Beckman Coulter DU 640 Spectrophotometer (Beckman Coulter, Brea, CA, USA) and Agilent 2100 Bioanalyzer (Agilent, Santa Clara, CA, USA), following the manufacturer's protocols.

\section{Gene array processing and statistical analysis}

The biotinylated single-stranded cDNA was prepared from 100 ng total intact RNA extracted from uninfected mouse control samples. Mouse mucosa at 8 hours and 4 days post infection was collected. Mouse cDNA was hybridized to the Mouse Gene 1.0 ST array, a microarray chip containing 28,000 sequenced mouse genes (Affymetrix). After hybridization, the array was washed and stained with streptavidin-phycoerythrin, and scanned in a proprietary Affymetrix scanner, according to the GeneChip Whole Transcript Sense Target Labeling Assay manual. The fluorescence values for each feature on the array were measured and recorded. Command Console software (Affymetrix) was used to produce a CEL file. All procedures were performed in three biological replicates at the Functional Genome Center of the University of Rochester. The data were processed with Expression Console (Affymetrix) using the PLIER algorithm (Affymetrix Guide to Probe Logarithmic Intensity Error (PLIER) 
Estimation. http://www.affymetrix.com/support/technical/technotes/plier_technote.pdf), which uses quantile normalization. Fold change was calculated for each strain relative to the uninfected control. Statistical significance ( $\mathrm{p}$ value) was calculated by Student's $t$ test, based on the results of three arrays per condition. Insignificant genes that changed by less than 1.2 fold and $p$ value $>0.05$ were removed from subsequent analysis. We set 1.2 as the cut-off $(\mathrm{p}<0.05)$ standard in order to analyze more genes involved in intestinal homeostasis and this cut-off is acceptable in the field $[35,36]$. The false discovery rate ( $Q$ value) was calculated for each $P$-value using $\mathrm{R}$ program according to the Storey and Tibshirani method [37]. We also estimated false discovery rate using Significance Analysis of Microarrays [38]. The microarray data used in this analysis have been submitted to NCBI GEO database under accession number GSE22215.

\section{Functional interpretation of microarray data as well as pathway and network analysis}

Ingenuity Pathways Analysis (IPA) (Ingenuity Systems http://www.ingenuity.com) is a web-based software application tool which is designed to organize biological information in a way that allows one to gain a high level overview of the general biology that is associated with microarray data [39-41].

In this study, the biofunctional analysis identified the molecular and cellular function that was most significant to the data set as a whole, thus generating functional interpretation of microarray data. Fischer's exact test was used to calculate a p-value determining the probability that each biofunction assigned to that data set is due to chance alone. IPA Canonical Pathways Analysis tool was used to identify the signaling and metabolic pathways associated with the database. Genes from the dataset that met the fold change cut-off of 1.2 were considered for the analysis. The significance of the association between the dataset and the canonical pathway was measured in two ways, the ratio and the significance. The ingenuity network analysis was used to display an interactive graphical representation of the interrelationships between molecules.

\section{Real-time quantitative reverse transcriptase PCR}

Quantitative PCR technology was used to verify the differential expression of 23 genes, including some genes around the two networks IFN- $\gamma$ and TNF- $\alpha$, at early and late response stages as identified by the microarray. Total RNA was reverse transcribed with oligoDT primer using an Invitrogen SuperScript III kit. The cDNA was subject to qRT-PCR using SYBR Green Supermix (BioRad, Hercules, CA, USA). Primers of target genes are listed in Additional file 1 Table S1. The amplification conditions were optimized for the MJ research DNA Engine instrument, using melting curve and electrophoresis analysis. The threshold cycle $(\mathrm{Ct})$ was determined, i. e., the cycle number at which the fluorescence of the amplified product crosses a specific threshold value in the exponential phase of amplification. Relative quantification of target gene expression was evaluated using the comparative cycle threshold $\left(C_{\mathrm{T}}\right)$ method as previously described by Livak and Schmittgen [42]. A value of $\mathrm{p} \leq$ 0.05 was considered statistically significant. Correlation analysis was performed by comparing expression ratios from the microarray results with the ratios tested by the qRT-PCR analysis. The Pearson correction coefficient between the qRT-PCR and microarray was analyzed.

\section{Salmonella-induced mouse cytokine secretion}

Mouse blood samples were collected by cardiac puncture and placed in tubes containing EDTA $(10 \mathrm{mg} / \mathrm{ml})[43,44]$. Mouse cytokines were measured using mouse cytokine 10-Plex Panel kit (Invitrogen) according to the manufacturer's instructions. Briefly, beads of defined spectral properties were conjugated to protein-specific capture antibodies, and then samples were added (including standards of known protein concentration, control samples, and test samples) into the wells of a filter-bottom microplate where proteins bound to the capture antibodies over the course of a 2 hour incubation. After washing the beads, protein-specific biotinylated detector antibodies were added and incubated with the beads for 1 hour. After removal of excess biotinylated detector antibodies, streptavidin conjugated to the fluorescent protein, then R-Phycoerythrin (Streptavidin- RPE) was added and allowed to incubate for 30 minutes. After washing to remove unbound Streptavidin-RPE, the beads were analyzed with the Luminex detection system (PerkinElmer CS1000 Autoplex Analyzer, Covina, CA, USA) [45].

\section{Immunoblotting}

Mouse colonic mucosa was collected by scraping the mouse colon, including proximal and distal regions [46]. Cells were sonicated in lysis buffer (1\% Triton X-100, $150 \mathrm{mM} \mathrm{NaCl}, 10 \mathrm{mM}$ Tris pH 7.4, $1 \mathrm{mM}$ EDTA, 1 mM EGTA pH 8.0, $0.29 \mathrm{mM}$ sodium ortho-vanadate, protease inhibitor cocktail). The protein concentration was measured using BioRad Reagent (BioRad). Cultured cells were rinsed twice in ice-cold HBSS, lysed in protein loading buffer (50 mM Tris, pH 6.8, $100 \mathrm{mM}$ dithiothreitol, 2\% SDS, $0.1 \%$ bromophenol blue, 10\% glycerol), and sonicated. Equal amounts of protein were separated by SDS-polyacrylamide gel electrophoresis, transferred to nitrocellulose, and immunoblotted with primary antibodies. The following antibodies were used: monoclonal Rabbit anti-Akt (Cell Signal, Beverly, MA, USA), Anti-Villin (Santa Cruz Biotechnology, Santa 
Cruz, CA, USA) and anti-actin (Sigma-Aldrich, Milwaukee, WI, USA).

\section{Histology and immunofluorescence of mouse colon}

Colonic tissues from the proximal and distal portion of the colon were freshly isolated and embedded in paraffin wax after fixation with $10 \%$ neutral 10 buffered formalin. Sections $(5 \mu \mathrm{m})$ were stained with hematoxylin and eosin $(\mathrm{H}$ and E). For immunofluorescence microscopy, tissue samples were processed for immunofluorescence as described previously $[43,44,47-49]$. In short, tissue samples were blocked in PBS containing 5\% BSA and 10\% goat serum, then incubated overnight with Sheep anti-Brdu (treated sample using HCL for 90 min before incubating) or Rrabbit anti-Akt antibodies. Immunofluorescence staining was performed by utilizing red fluorescent anti-sheep or antirabbit IgG (Alex 594, Invitrogen) for one hour, then cover slips were washed three times with PBS $(10 \mathrm{~min} / \mathrm{each}$ time). DAPI was added in the final wash, then mounted with SlowFade (SlowFade ${ }^{\circ}$ AntiFade Kit, Molecular Probes, Invitrogen) and followed by a cover slip. Edges were sealed to prevent drying. Samples were viewed with an Olympus Ax70 microscope. Captured images were analyzed using Image-pro plus 5.0 software.

\section{Results}

\section{Global gene differential expression during the time course of Salmonella infection in the mouse colon mucosa}

In this current study, we focused on the mouse colon mucosa's responses to Salmonella infection at both 8 hours and 4 days post infection in vivo. Previous studies indicate that the 8 hours post-infection provides insights into the early events of Salmonella infection in the colon, whereas investigation of the gene expression response at 4 days post-infection can show the outcome of infection and inflammation $[43,44,47,48]$. Hence, we selected genes that changed in response to Salmonella infection at 8 hours and 4 days. In total, we hybridized 9 different samples (3 individual mice from each of the three groups) to the microarray chip in this study.

FDR and nominal $P$ were similar at 4 days, the analysis was based on the nominal P values (all FDR values < $10 \%$ when nominal $\mathrm{P}<0.05)$. At 8 hours, the FDR values were high for all probe sets (>46\%). However, we included this time point because it allows us to investigate how many genes began to respond at the early stage of infection and how many genes are dependent on the time-course responses.

\section{Top differentially regulated genes in response to infection}

Differential expression analyses between the normal control and the Salmonella-infected group were carried out with GeneSifter software (VizX Labs, Seattle, WA). GeneSifter $^{\mathrm{TM}}$ is unique in the field of microarray data analysis software because it is the only package that is wholly web-based http://www.geospiza.com/Products/ AnalysisEdition.shtml. Of the 28,000 genes represented on the array, our analysis of mRNA expression in mouse colon mucosa showed that a total of 856 genes were expressed differentially (Figure 1A and Additional file 2 Table S2) in the pathogenic SL1344 infected group at 8 hours. Of these 856 genes, 453 genes (53\%) were up-regulated and 403 (47\%) were down-regulated. 99\% selected genes showed 1.2-2 fold times change (Figure $1 \mathrm{~A}$, black and white). There were only 4 up-regulated and 5 down-regulated genes with a fold change range from 2 to 5 times.

At 4 days post-infection, we identified 7558 genes that were expressed differentially (Additional file 3 Table S3). The majority of the selected genes showed moderate alterations in expression of between 1.2 and 2.0 fold (Figure 1B). Figure 1B also showed that 389 up-regulated genes and 681 down-regulated genes with a fold change range from 2 times to 5 times, 69 up-regulated genes and 50 down-regulated genes with a fold change range from 5 times to 10 times, and 75 up-regulated genes and 24 down-regulated genes with a fold change greater than 10 times. The data for differentially expressed genes are shown in Table S2-S3.

For the differential expression genes between animals infected for 8 hours and 4 days, we identified 7127 genes that were expressed differentially during two time course (Additional file 4 Table S4). Total 4951 genes (69\% genes) showed down-regulated and 2176 genes (31\%) showed up-regulated. 3798 down-regulated genes between animals infected for 8 hours and 4 days showed the similar expression pattern as the gene list between the control and 4 days post-infection group. Therefore, we focused on the differential expression between non infected and infected mice at either 8 hours or 4 days post-infection.

Two genes, Hist1hle and Arnt1 showed up-regulated between 4 days post-infection and the control group without treatment, but showed down-regulated between 4 days post-infection and 8 hours post-infection. The up-regulated 1328 genes between 4 days and 8 hours post-infection showed the similar expression pattern as the genes between 4 days post-infection to control. Other 846 up-regulated genes were new responses between 4 days and 8 hours post-infection, and $90 \%$ of these genes had a fold change range from 1.2 times to 2 times. Three genes, Olfr1257 and other two unknown genes, were down-regulated between 4 days post-infection and control, but up-regulated between 4 days postinfection and 8 hours post-infection. Overall, the data indicate that pathogenic Salmonella regulates the gene 


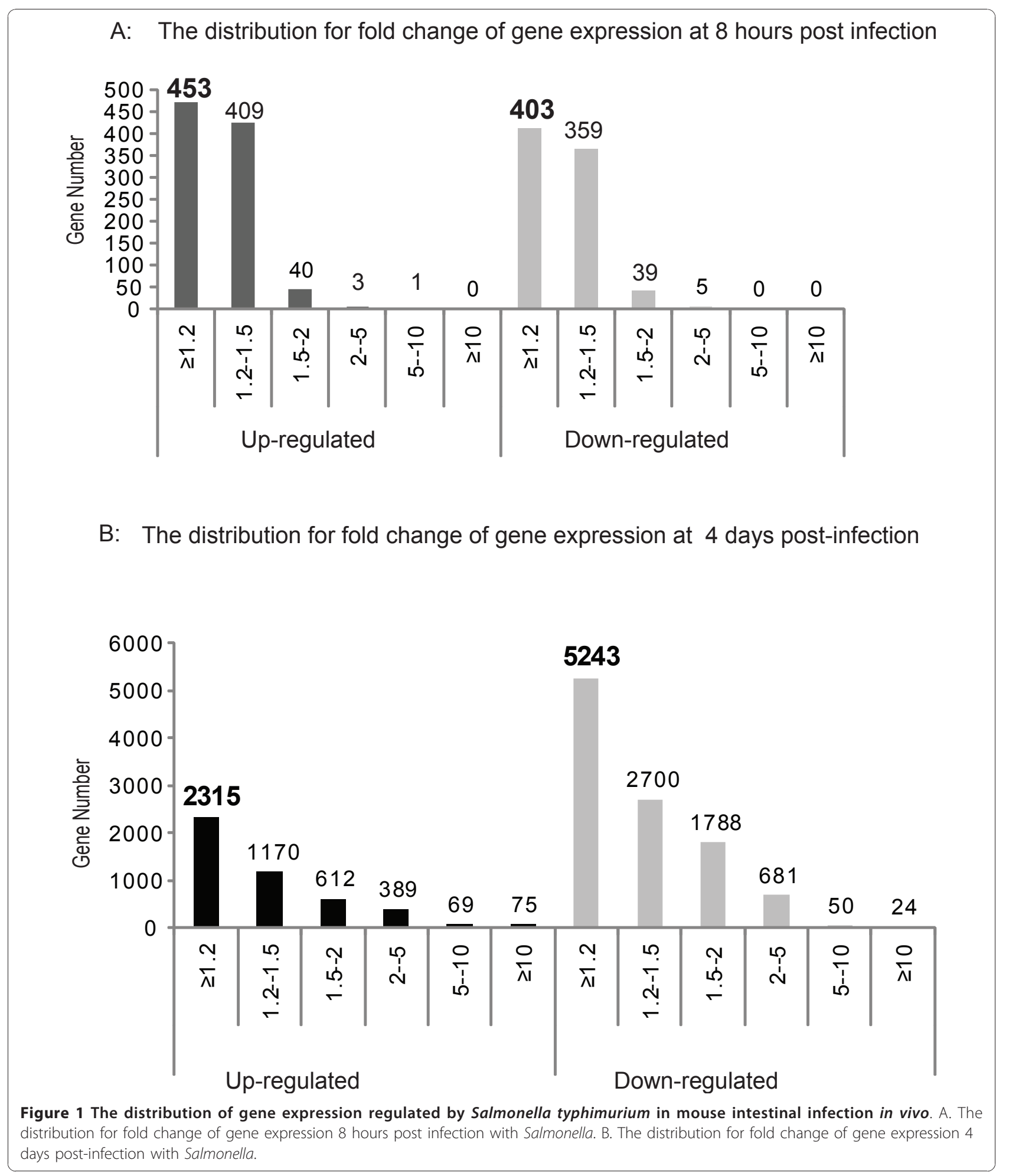

expression in intestinal mucosa at the early stage of infection, but more profound changes in gene expression occurred in the late stage of infection.

We further analyzed the top up-regulated and downregulated genes in every infection group to identify the specific responses induced by Salmonella-infection (Table 1). Of the 10 annotated up-regulated genes in SL1344 infection at 8 hours, RETNLB as a colon-specific gene has been reported to associate with bacteria infection, and RETNLB in situ hybridization occurs in 
Table 1 Top-differentially expressed gene list at 8 hours and 4 days post-infection

\begin{tabular}{lllllllll}
\hline SL1344 infection at 8 hr & \multicolumn{3}{l}{ SL1344 infection at 4 day } \\
\hline Up-regulated & \multicolumn{3}{l}{$\begin{array}{l}\text { Down- } \\
\text { regulated }\end{array}$} & \multicolumn{2}{l}{ Up-regulated } & $\begin{array}{l}\text { Down- } \\
\text { regulated }\end{array}$ \\
\hline Gene Name & Fold & $\begin{array}{l}\text { Gene } \\
\text { Name }\end{array}$ & Fold & $\begin{array}{l}\text { Gene } \\
\text { Name }\end{array}$ & Fold & $\begin{array}{l}\text { Gene } \\
\text { Name }\end{array}$ & Fold \\
\hline RETNLB & 5.2 & TRDN & -3.4 & CXCL5 & 310.8 & CYP2C18 & -72.7 \\
2010109103RIK & 2.2 & SGK1 & -3.0 & S100A8 & 221.5 & CES1 & -33.1 \\
NOV & 2.0 & PLK3 & -2.4 & LRG1 & 217.5 & CES3 & -28.6 \\
SERPINB12 & 1.7 & EDN2 & -2.1 & LCN2 & 184.1 & NOV & -27.1 \\
CAPG & 1.7 & SLC37A2 & -2.0 & S100A9 & 144.7 & B3GNT6 & -24.3 \\
IMPDH2 & 1.7 & EMX2 & -2.0 & LTF & 117.7 & SSTR1 & -18.5 \\
TIPIN & 1.7 & TP53INP1 & -1.9 & CCL8 & 111.1 & ARHGAP20 & -15.6 \\
FBXW12 & 1.7 & SSTR1 & -1.9 & IIGP1 & 93.2 & ODF3B & -15.0 \\
FDPS & 1.7 & C1ORF51 & -1.8 & NOS2 & 94.0 & SULT1A1 & -13.5 \\
ACOT9 & 1.7 & TGFBI & -1.8 & GBP4 & 84.6 & CYP4B1 & -13.5 \\
\hline
\end{tabular}

proliferative mouse epithelial cells [50]. IPA data base showed RETNLB and FDPs were associated with endocrine system disorders; CAPG, ACOT9, FDPS, and $I M P D H 2$ were associated with genetics disorder. $C A P G$ encodes a member of the gelsolin/villin family of actinregulatory proteins. By capping the barbed ends of actin filaments, the encoded CAPG protein contributes to the control of actin-based motility in non-muscle cells [51]. Salmonella effector proteins promote bacteria internalization by binding to actin and directly modulating actin dynamics [52-54]. CAPG may be involved in regulation of actin microfilament remodeling which is required for Salmonella invasion at the early stage of infection. IPA data base showed that NOV, TIPIN, and IMPDH2 are associated with cellular growth and proliferation. TIPIN has been shown to interact with Replication protein A [55]. It is also associated with the cell cycle and DNA replication [56]. The other 2 up-regulated genes, 2010109I03RIK and FBXW12 are associated with bioprocess and molecular function and diseases.

Of the top 10 annotated down-regulated genes in SL1344 infected group at 8 hours, we found most of the genes were relative to the cell cycle and cell death process: TP53INP1, SGK1, SSTR1 and EMX2 were involved in cell cycle; TP53INP1, TGFBI, SGK1 and PLK3 were involved in cell death. The result supports that Salmonella infection plays a role in regulating the host's cell cycle and cell death process at early stages of infection, as we reported in a recent study [57].

At 4 days post-infection, of the 10 annotated up-regulated genes, $70 \%$ genes are involved in inflammatory response and bacterial infection; only $L G R 1$ is involved in connective tissue development. Interestingly, S100 family proteins are involved in the regulation of a number of cellular processes, and two members of this gene family, $S 100 A 8$ and $S 100 A 9$, were significantly upregulated with a large fold change at 4 days post infection relative to non-infected mouse. In agreement with our results, Rodenburg et al also reported up-regulation of S100A8 and S100A9 in the rat colonic mucosa infected by Salmonella [58].

Of the top 10 annotated down-regulated genes in SL1344 infected at 4 days (Table 1), 80\% genes were involved in the regulation of cell cycle, cellular growth and proliferation and metabolism process, but SSTR1 was also involved in inflammatory response. Interestingly, SSTR1 showed continual down-regulation at both 8 hours and 4 days post-infection. The SSTR 1 gene encodes a protein called somatostatin receptor type 1 . Somatostatin plays an important role in many physiological processes, such as growth hormone release, cell anti-proliferation, and inhibition of gastrointestinal motility and regulate a variety of signal transduction pathways [59-61]. Moreover, we found that there are three protein families in this list that are involved in xenobiotic metabolism, such as cytochrome P450 (CYP4B1 and CYP2C18), sulfotransferase (SULT1A1), and carboxylesterase (CES1 and CES3). Downregulation of Cytochromes P450 (CYPs) in intestinal epithelium was also shown in response to chicken with Salmonella infection [62] and proinflammatory cytokines [63,64].

Relevant functions, pathways, and biological networks in intestinal mucosa post Salmonella infection

In order to identify the gene function and associated biological process for all of differentially expressed genes, the 453 up-regulated genes and 403 down-regulated genes in the 8 hours post-infection group (Figure $1 \mathrm{~A}$ ), and the 2315 up-regulated genes and 5243 downregulated genes in the 4 days post-infection group (Figure $1 \mathrm{~B}$ ), were assigned to Ingenuity Pathways Analysis (IPA). In total, 229 up-regulated and 254 down-regulated GeneIDS at the 8 hours post-infection group, and 1427 up-regulated and 3368 down-regulated GeneIDS at the 4 days post-infection group, were eligible to biological process and gene network.

An over-representation of a specific biological process does not indicate whether the process in question is being stimulated or repressed overall. The interaction of Salmonella with intestine is a key event in the early phases of infection. Still, the signaling steps taking place during this interaction remain largely unknown. Therefore, we used IPA software to further investigate overor under-represented pathway responses by Salmonella infection. In order to further investigate the global expression response to infection with Salmonella and to define how individual up-regulated and down-regulated genes interact to have a coordinated role in specific pathways, we further identified potential networks of 
response to Salmonella infection at the early stage and late stage, respectively.

\section{Relevant functions, pathways, and biological networks 8 hours post infection}

In the 8 hours post-infection group, major functional gene categories were especially up-regulated by Salmonella infection including DNA replication, recombination and repair, cellular assembly and organization, cellular function and maintenance, and metabolism (Figure 2A). Down-regulated genes at 8 hours post-infection were functionally associated with cellular development and carbohydrate metabolism, molecular transport, and small molecular biochemistry (Figure 2C). However, pathways linked to gene expression and the cell cycle displayed altered regulation (Figure $2 \mathrm{~A}$ and $2 \mathrm{C}$ ). The top canonical signaling and metabolic pathways within all of differentially expressed genes at 8 hours post infection group are shown in Figure 3. All the pathways that were affected showed lower significance, which indicated that the pathways linked to these genes had no profound change for cell signaling and transduction at the early stage of infection.

As shown in Figure 3 the most significant pathway associated with differentially expressed genes in 8 hours post-infection is oxidative phosphorylation. The up-regulated genes involved in the pathway were localized in the mitochondria. Accordingly, we found that the pathway related to mitochondrial dysfunction is affected (Figure 3 ). These data suggested that the signaling response for mitochondrial function is a major event at the early stage of infection. Moreover, we found that most of genes associated with p53 signaling are down-regulated (Figure 3 and Additional file 5 Table S5). Significantly, there was prominent down-regulation mRNA level of TP53.

We further identify the network at 8 hours post Salmonella infection. Network 1 consists of 26 DEGs genes that almost all interact directly with nuclear factorkappa B transcription factor $(\mathrm{NF}-\kappa \mathrm{B}$ ) (Figure 4 and Additional file 6 Table S6). NF- $\kappa$ B pathway has been previously reported to be activated by Salmonella infection [12,65-67]. Our data showed that the network 1 is associated with Cellular Assembly and Organization (ENG, TRIP6ANXA1, ANXA2ITGB1BP1, CAPN10), Cellular Function and Maintenance (ANX1 MUC1), Antigen Presentation (ANXA1, ANXA2, IL18RAP CD69) and Inflammatory Response (ANXA1, ANXA2, CD69, GPX1, IFITM2, IL18RAP, MX2).

Overall, we identified 14 highly significant networks of potentially interacting up-regulated genes at 8 hours post-infection group (Additional file 7 Table S7). The highest ranked network is provided as Figure 4. However, for down-regulated genes at 8 hours post infection, we identified 16 highly significant networks of potentially interacting down-regulated genes (Additional file 8
Table S8) and did not identify a network with center regulation.

\section{Relevant functions, pathways, and biological networks 4 days post infection}

In the 4 days post-infection group (Figure 2B), major functional gene categories that were specifically up-regulated in Salmonella infection included cell-to-cell signaling and interaction, cellular movement, cellular development, antigen presentation, cell death, cellular growth and proliferation, and cellular function and maintenance. The pathways associated with RNA posttranscriptional modification, DNA replication, recombination, and repair, protein synthesis, lipid metabolism, post-translational modification and cell cycle were down-regulated (Figure 2D), whereas pathways linked to gene expression displayed altered regulation (Figure $2 \mathrm{~B}$ and 2D).

We identified canonical pathways involving signaling that is associated with differential genes at 4 days postinfection (Additional file 9 Table S9 and Table 2). Table 2 lists the 20 most significant pathways for fold $\geq 1.2$. As shown in Table 2 diverse and complex signals related to cell growth and proliferation, apoptosis signal, and cell immune/inflammatory transduction pathways are involved in the colon mucosa at 4 days post-infection.

These data revealed a unique landscape where induction of certain pathways limits the inflammatory response (e.g., IL-4, IL-9 and Interferon signaling), and was coupled with promoting the inflammatory response, such as acute phase response signaling and glucocorticoid receptor signaling. Pathway analysis revealed that two signaling pathways related to protein synthesis (EIF2 signaling as well as Role of PKR in Interferon induction and antiviral response) and three pathways related to lipid metabolism (Xenobiotic metabolism signaling, LPS/IL-1-mediated inhibition of RXR function, and LXR/RXR activation) were inhibited by Salmonella infection. Two pathways most related to cell growth and proliferation (IL-9 signaling and EGF signaling) were activated by Salmonella infection (Additional file 10 Figure S1 EGF and Figure S2 IL-9), but two pathways, Insulin receptor signaling and Estrogen receptor signaling related to cell growth and proliferation were inhibited. Three pathways most related to cell death and apoptosis (NRF2-mediated Oxidative Stress Response, p38 MAPK signaling and LPS-stimulated MAPK signaling) were activated.

We identified canonical pathways involving metabolism that are associated with differential genes at 4 days post infection. Figure 5 Additional file 11 Table S11, and Additional file 12 S12 show most of the genes involved in these metabolic pathways and all the metabolism pathways involved in mouse mucosa infection. Valine, leucine, and lsoleucine degradation and carbohydrate metabolism are the two most significant pathways in the analysis list. The 


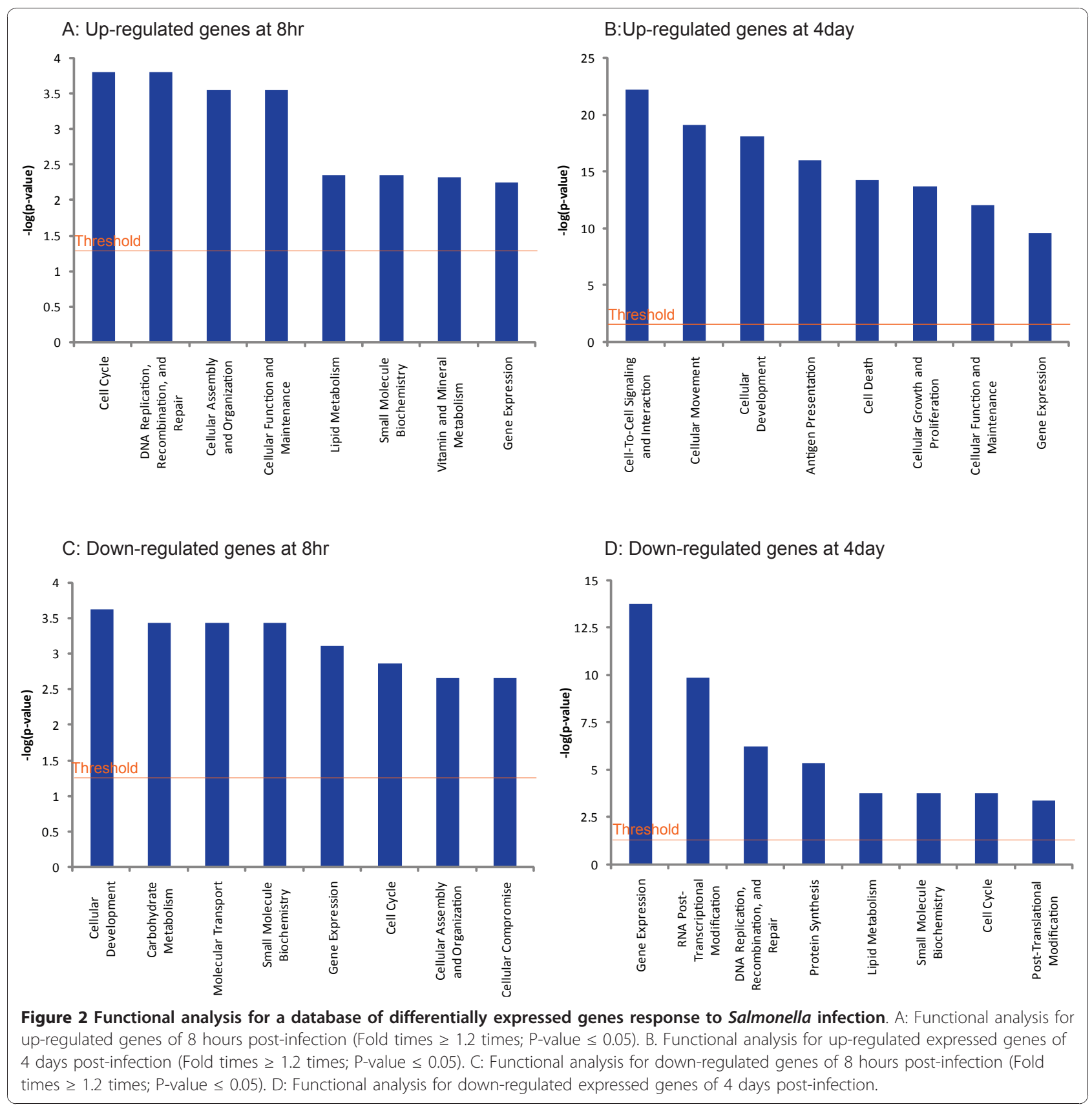

top function of valine, leucine, and isoleucine degradation involves lipid metabolism, molecular transport, and nucleic acid metabolism.

Moreover, we identified 23 highly significant networks of interacting genes from amongst the up-regulated genes at 4 . days post-infection group (Additional file 13 Table S13). For down-regulated genes, we identified 23 networks (Additional file 14 Table S14). The two highest ranked networks, IFN- $\gamma$ and TNF- $\alpha$, are provided in Figure 6 and Figure 7.

IFN- $\boldsymbol{\gamma}$ Network 2 presents IFNG (IFN- $\gamma$ ) in central positions and consists of 35 DEGs genes that are all regulated positively by IFN- $\gamma$ (Figure 6A and Additional file 15 Table S15). The network is correlated with following functions: cell growth and proliferation (C190RF10, IFNG, LY6E, $A T F 1$ and IRGM), inflammatory response (IFNG, IRGM, CD274 and IFI44), lipid metabolism (IFNG, DPAGT1, PHGDH, H6PD, GBP5, and GPR109A), and small molecule biochemistry (IFNG, DPAGT1, PHGDH, LY6E, H6PD, GBP5, and GPR109A). Microarray data showed that all genes in the network were prominently up-regulated.

In order to confirm the physiological relevance of IFN- $\gamma$ in vivo, we further investigated the secretion of 


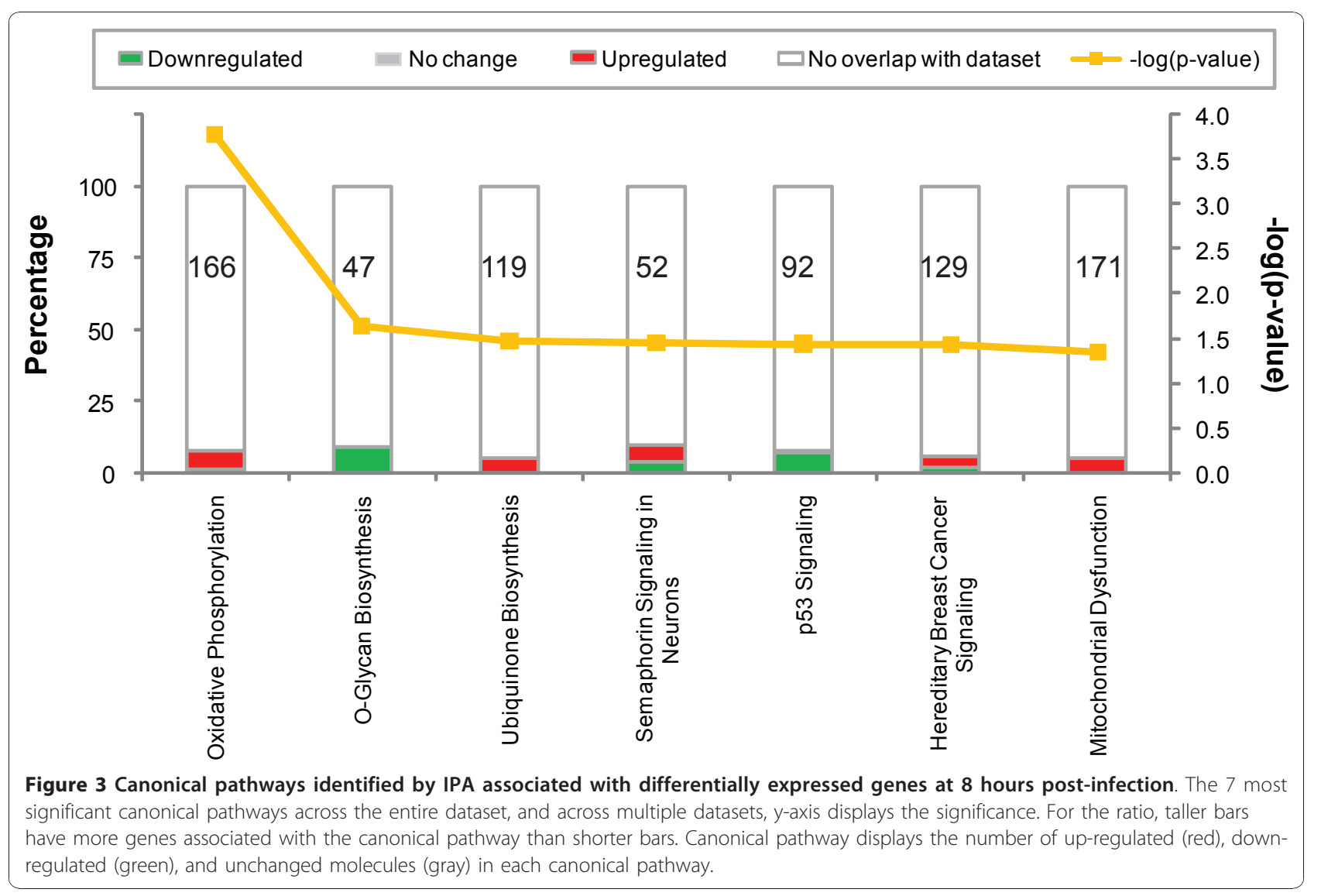

the IFN- $\gamma$ cytokine in mouse serum. In Figure 6B, significant differences were found between control and 4 days post-infection. Using real-time PCR, we further verified the expression of some genes in the IFN- $\gamma$ network (Figure 6C). IFNG, GBP4, and GBP5 showed dramatic increase post Salmonella infection.

TNF- $\alpha$ The network3 presents TNF (TNF- $\alpha$ ) in central positions and consists of $28 \mathrm{DEGs}$ genes that are all positively regulated by TNF- $\alpha$ (Figure 7A and Additional file 16 Table S16). The network is linked to the following functions: nucleic acid metabolism (SLC28A2), lipid metabolism (PDPN, ASAH1, LSS, NAMPT and TNF), small molecule biochemistry (ASAH1, LSS, NAMPT, TNF and SLC28A2), cell death (NAMPT, TNF, CHI3L1 and $A S A H 1)$, hematological system development and function (CHST4, TNF and SLFN12L), immune cell trafficking (CHI3L1, TNF and CHST4), cellular function and maintenance (CTSZ and TNF), genetic disorder (ASAH1 and $B T N L 2)$, inflammatory disease (BTNL2 and TNF), antigen presentation (CTSZ and TNF), cellular growth and proliferation (C11ORF82, SLFN12L and TNF), and inflammatory response (OAS1 and TNF).

We also investigated the secretion of the TNF- $\alpha$ cytokine in mouse serum. In Figure 7B, significant difference was found between control and 4 days post infection.
Moreover, the expressions of some genes from the TNF- $\alpha$ network were verified using real-time PCR assay (Figure 7C).

NR3C1 The NR3C1 protein is a receptor for glucocorticoids that can act as both a transcriptional factor and as a regulator of other transcription factors. As shown in Figure 8 and Additional file 17 Table S17, NR3C1 was in the central position of the network. This network was consisted of 35 down-regulated genes that are all positively regulated by NR3C1. We observed that top functions these genes involved are RNA post-Transcriptional Modification (CLP1 TSEN2 and TSEN54) and infectious disease and inflammatory disease (NR3C1, PPP3CC, and PPP3R1). Down-regulation of this gene is caused by glucocorticoid resistance, or cortisol resistance. Currently, glucocorticoid resistance or insensitivity is a major barrier in the treatment of several common inflammatory diseases [68].

\section{Co-regulated biological and common pathways at both times post Salmonella infection}

The IPA analysis confirmed the major functionally related groups that were found to be commonly up-or down-regulated in both of the time-point infection groups. Thus, the pathways functionally linked to cell function and maintenance were induced at both the early stage and late 

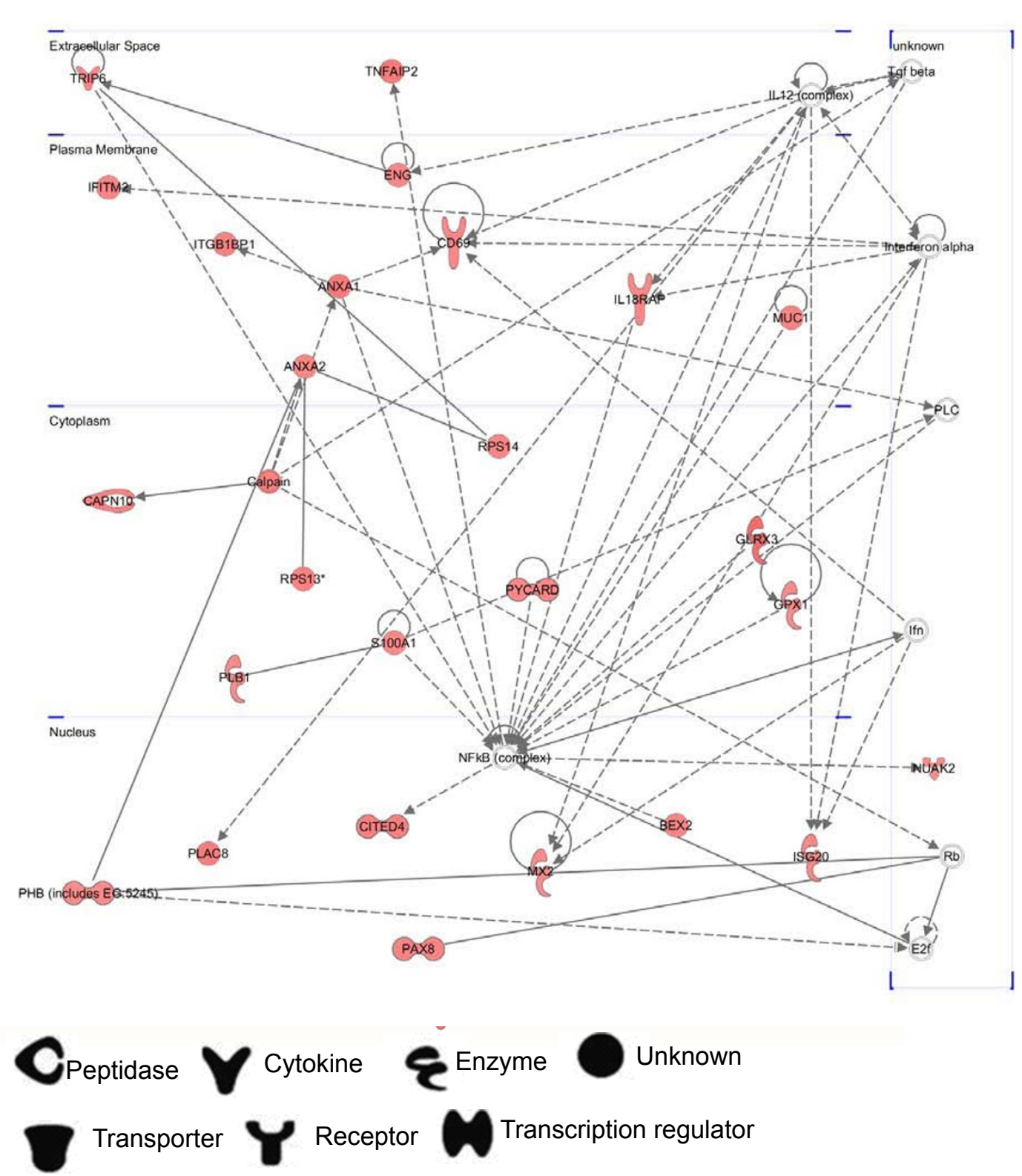

Figure 4 Ingenuity pathway analysis network 1 depicting relationships among up-regulated genes at the 8 hr post-infection. Intensity of the red color indicates the degree of up-regulation. Nodes are displayed using various shapes that represent the functional class of the gene product. Edges are displayed with various labels that describe the nature of relationship between the nodes: represents direct relationship; represents indirect relationship; $\rightarrow$ represents acts on.

stage of infection (Figure 2A and 2C). The pathways functionally related to cell cycle control and gene expression displayed suppression in Salmonella infection at both time points (Figure 2B and 2D), whereas the pathway functionally related to lipid metabolism showed up-regulation in response to Salmonella infection at early stage, but showed down-regulation at the late stage of 4 days post infection.

To investigate the co-regulated biological processes during the early and late stages of SL1344 infection, we searched for co-differentially expressed genes among both groups. A set of 43 genes was found to be commonly up-regulated in response to Salmonella infection at the early and late stage of infection (Additional file 18 Table S18). The top five functional categories associated with these common up-regulated genes are as follows: cellular assembly and organization (DYNLT1, ANXA1, BARD1, SRF, ANXA2, ENG and TMSB10); cellular development (MUC1, DYNLT1, PCSK9, ANXA1, SRF, CAPG, JUNB, ENG and PLAC8); gene expression 
Table 2 Canonical pathways identified by IPA associated with differentially expressed genes of 4 days post-infection ( $p \leq 0.05$; fold times $\geq 1.2$ times. +: activation; -: inhibition).

\begin{tabular}{|c|c|c|c|c|c|}
\hline Ingenuity signaling Pathways & $\begin{array}{l}-\log (p- \\
\text { value) }\end{array}$ & Ratio & $\begin{array}{l}\text { Up/ } \\
\text { down }\end{array}$ & Effect & Function (From IPA) \\
\hline NRF2-mediated Oxidative Stress Response & 5.25E00 & $\begin{array}{l}4.37 \mathrm{E}- \\
01\end{array}$ & $24 / 56$ & + & Cell Death; Developmental Disorder \\
\hline Antigen Presentation Pathway & 3.79E00 & $\begin{array}{l}4.36 \mathrm{E}- \\
01\end{array}$ & $17 / 0$ & + & $\begin{array}{l}\text { Genetic Disorder; Immunological Disease Gene Expression; } \\
\text { Infection Mechanism }\end{array}$ \\
\hline Estrogen Receptor Signaling & 3.47E00 & $\begin{array}{l}4.37 \mathrm{E}- \\
01\end{array}$ & $4 / 48$ & - & Cellular Growth and Proliferation \\
\hline Xenobiotic Metabolism Signaling & 3.57E00 & $\begin{array}{l}3.60 \mathrm{E}- \\
01\end{array}$ & $30 / 75$ & - & $\begin{array}{l}\text { Lipid Metabol is m; Small Molecule Biochemistry Vitamin and } \\
\text { Mineral Metabolism }\end{array}$ \\
\hline IL- 9 Signaling & 3.4E00 & $\begin{array}{l}5.41 \mathrm{E}- \\
01\end{array}$ & $12 / 8$ & + & Cell Death; Cellular Growth and Proliferation \\
\hline EIF2 Signaling & 3.32E00 & $\begin{array}{l}4.2 \mathrm{E}- \\
01\end{array}$ & $10 / 32$ & - & $\begin{array}{l}\text { Protein Synthesis; Amino Acid Metabolism; Post-Translational } \\
\text { Modification }\end{array}$ \\
\hline Glucocorticoid Receptor Signaling & 2.79E00 & $\begin{array}{l}3.64 \mathrm{E} \\
01\end{array}$ & $39 / 63$ & + & $\begin{array}{l}\text { Cellular Development; Gene Expression; Cellular Growth and } \\
\text { Proliferation }\end{array}$ \\
\hline Regulation of elF4 and p70S6K Signaling & 2.74E00 & $\begin{array}{l}3.85 \mathrm{E}- \\
01\end{array}$ & $11 / 39$ & - & Gene Expression; Protein Synthesis and Cancer \\
\hline $\begin{array}{l}\text { Role of PKR in Interferon Induction and } \\
\text { Antiviral }\end{array}$ & 2.73E00 & $5 \mathrm{E}-01$ & $17 / 6$ & + & Cell Death; Cellular Development; Immune Response \\
\hline $\begin{array}{l}\text { DNA Methylation, Transcriptional } \\
\text { Repression Signaling }\end{array}$ & 2.51E00 & $\begin{array}{l}5.65 \mathrm{E}- \\
01\end{array}$ & $0 / 13$ & - & $\begin{array}{l}\text { Gene Expression; DNA Replication, Recombination and Repair; Cell } \\
\text { Cycle }\end{array}$ \\
\hline IL-4 signaling & 2.47E00 & $\begin{array}{l}4.46 \mathrm{E} \\
-01\end{array}$ & $19 / 14$ & + & Cellular Development; Hematopoietic \\
\hline $\begin{array}{l}\text { LPS/IL-1 Mediated Inhibition of RXR } \\
\text { Function }\end{array}$ & 2.39E00 & $\begin{array}{l}3.49 \mathrm{E}- \\
01\end{array}$ & $27 / 48$ & - & Lipid Metabolism;Small Molecule Biochemistry \\
\hline $\begin{array}{l}\text { Retinoic acid Mediated Apoptosis } \\
\text { Signaling }\end{array}$ & 2.35E00 & $\begin{array}{l}\text { 4.09E- } \\
01\end{array}$ & $12 / 6$ & + & Cell Death; Embryonic Development; Cell Morphology \\
\hline EGF Signaling & 2.35E00 & $\begin{array}{l}4.69 \mathrm{E}- \\
01\end{array}$ & $9 / 14$ & + & Gene Expression; Cell cycle, Cellular Growth and Proliferation \\
\hline Interferon Signaling & 2.29E00 & $\begin{array}{l}5.33 \mathrm{E}- \\
01\end{array}$ & $15 / 1$ & + & $\begin{array}{l}\text { Organism Injury and Inflammatory Response Cellular Growth and } \\
\text { Proliferation }\end{array}$ \\
\hline P38 MAPK Signaling & 2.21E00 & $\begin{array}{l}4.23 \mathrm{E}- \\
01\end{array}$ & $21 / 20$ & + & Gene Expression; Cell Death; Cell Signaling \\
\hline LPS-stimulated MAPK Signaling & 2.2E00 & $\begin{array}{l}4.23 \mathrm{E}- \\
01\end{array}$ & $15 / 18$ & + & Cell Death; Gene Expression; Cellular Development. \\
\hline Insulin Receptor Signaling & 2.01E00 & $\begin{array}{l}3.86 \mathrm{E}- \\
01\end{array}$ & $14 / 40$ & - & Cancer; Carbohydrate Metabolism; Molecular Transport \\
\hline Acute Phase Response Signaling & 2E00 & $\begin{array}{l}3.96 \mathrm{E}- \\
01\end{array}$ & $10 / 9$ & + & $\begin{array}{l}\text { Hematological System Development and Function; Hematological } \\
\text { Disease; Cell Death }\end{array}$ \\
\hline mTOR Signaling & 1.99E00 & $\begin{array}{l}3.88 \mathrm{E}^{-} \\
01\end{array}$ & $41 / 28$ & + & Gene Expression; Protein Synthesis; Cell Morphology \\
\hline LXR/RXR Activation & 1.88E00 & $\begin{array}{l}4.14 \mathrm{E}- \\
01\end{array}$ & $9 / 20$ & - & $\begin{array}{l}\text { Lipid Metabolism; Molecular Transport; Small Molecule } \\
\text { Biochemistry }\end{array}$ \\
\hline
\end{tabular}

(MUC1, IL18RAP, SRF, JUNB, and ENG); cell growth and proliferation (MUC1, IL18RAP, BARD1, RRM2, SRF, ANXA2, JUNB, FGFBP1, ANXA1, CYBB, ENG, PLAC8 and TMSB10); cell death (MUC1, BARD1, CYBB, GMFG and TMSB10) (Additional file 19 Table S19). Interestingly, Mucin 1 (MUC1) was found to be involved in a variety of biological processes, and $M U C 1$ 's role in host defense has been revealed by McAuley JL et al (2007)[69].

A set of 173 genes was found to be commonly downregulated in response to Salmonella infection at both the early and late stage (Additional file 20 Table S20). The top five functional categories associated with these common down-regulated genes are shown in Additional file 21 Table S21. They are as follows: cellular development (KITLG, CBX7, SLC4A2, TBX3, STRBP, SAFB, ROBO2); cellular compromise (KITLG, PRSS23, NFE2L2); cellular movement (KITLG, NOV, NDEL1, LPAR1, HSF2, ROBO2, NFE2L2, SLC12A6); cell cycle (KITLG, BHLHE40, HSF2, CHKA, SSTR1, MNAT1); RNA post-transcriptional modification (YTHDC1, RBM16, PNN, RPS28, SAFB, RPL26, EXOSC7). Remarkably, KITLG was also found to be involved in a 


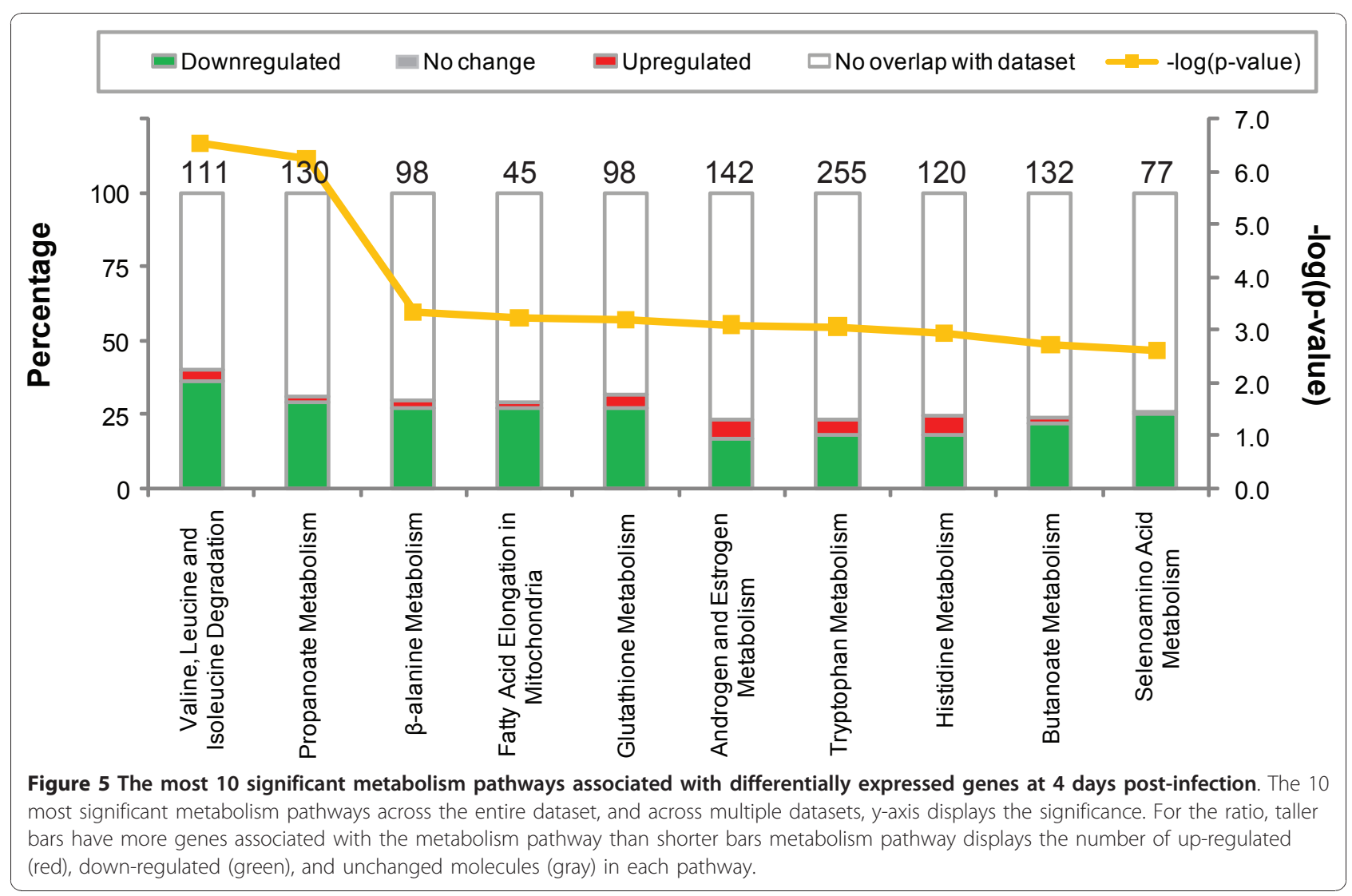

variety of biological processes (Table S7). The role of KITLG in the maintenance and survival of hematopoietic stem cells and of mast cells is well recognized [70] and was believed to play a role in tumorigenesis [71]. Downregulation of KITLG may inhibit cell migration and stem cell hemtopoiesis during the whole infection process.

In order to identity co-regulated pathway, we further performed pathway analysis. For these differentially expression genes between 8 hours pos-infection and 4 days post-infection, the metabolic pathways are shown in Figure S3 and the top canonical signaling pathways are in Figure S4. All of canonical signaling and metabolic pathway are listed in Tables S11 and S18. Comparing to 8 hours post-infection group, oxidative phosphorylation, ubiquinone biosynthesis, and mitochondrial dysfunction were totally shut-off at the 4 days post infection (Additional file 10 Figure S3 and S4). As shown in Table S18 (Additional file 18), most of signaling pathway list is similar to that of the pathway analysis for these genes between the 4 days post-infection group and the control group. The early modified signaling pathways, such as p53 signaling, was not maintained 4 days post infection. Moreover, pathway comparison analysis for the data of the 8 hours post-infection relative to control with the 4 days post-infection relative to control confirmed these results (Additional file 10 Figure S5).
Validation of differentially expressed genes by real-timePCR

To validate the microarray results, we analyzed 13 transcripts, in addition to the 10 genes from the IFN- $\gamma$ and TNF- $\alpha$ networks, by quantitative real time-PCR (Figure 9). These genes were selected because of their top ranking positions on the differentially expressed gene list at both time points. Results showed that all of genes exhibited a similar transcriptional profile to that of microarray data. The Pearson correction coefficient between the qRT-PCR and microarray data for 13 top ranking differentially expressed was 0.86 . Moreover, 10 genes with lower or medium fold change around both INF- $\gamma$ and TNF- $\alpha$ network (Figure 6 and Figure 7) were also analyzed using samples generated from infected animals. Real-time PCR results showed 9 genes were up-regulated with the similar transcriptional profile as that of microarray data, except IL1RN without any change. Hence, the microarray provided a reliable comparison of gene expression in mouse mucosa samples at 8 hours and 4 days post-infection.

Validation of differentially expressed genes at the protein level by Western blot

Akts are crucial mediators of various cellular processes, such as cell proliferation, apoptosis, regulation of the 
A

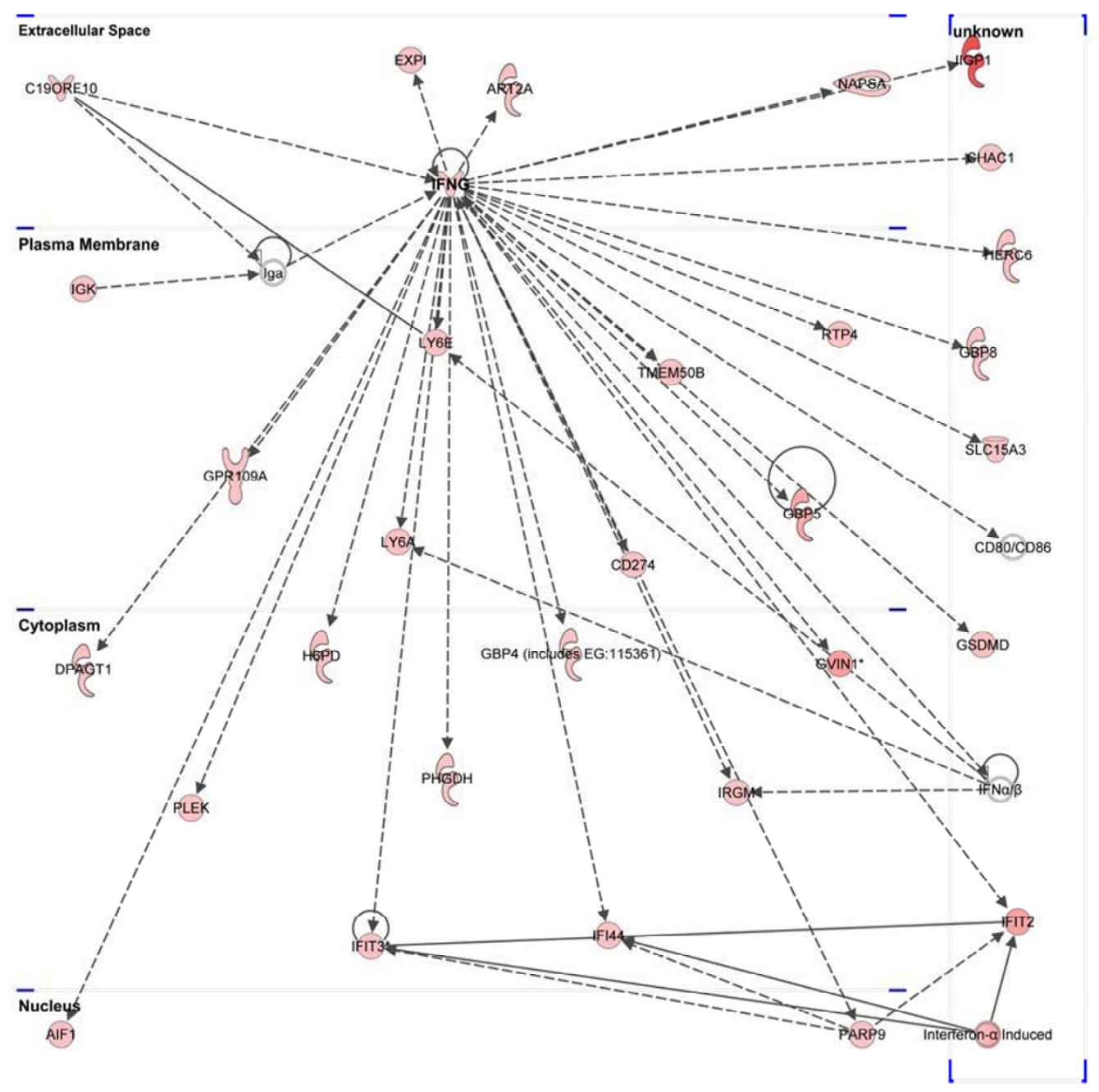

B

IFN-Y

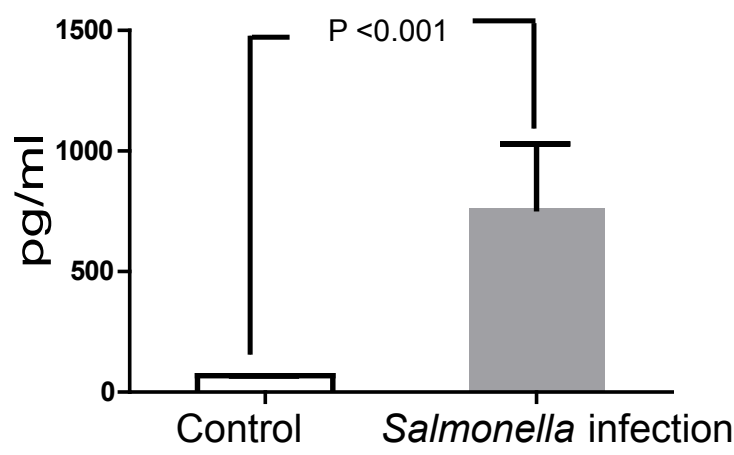

C

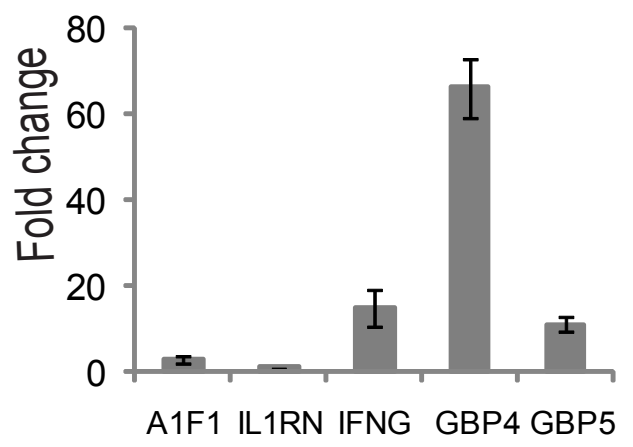

Figure 6 Ingenuity pathway analysis of the IFN- $\boldsymbol{\gamma}$ network. A. Ingenuity pathway Analysis network 2 depicting relationships among upregulated genes at 4 days post-infection. The intensity of the node color-(red)) indicated the degree of up-regulation. Edges are displayed with various labels that describe the nature of relationship between the nodes: _ represents direct relationship; _ _ — represents indirect relationship; $\rightarrow$ represents acts on .Nodes are displayed using various shapes that represent the functional class of the gene product same as shown Figure 6. B. Serum IFN- $\gamma$ levels in the control and the Salmonella infection group 4 days postinfection. C. Real-time PCR results for some targeted genes from the IFN- $\gamma$ network. 

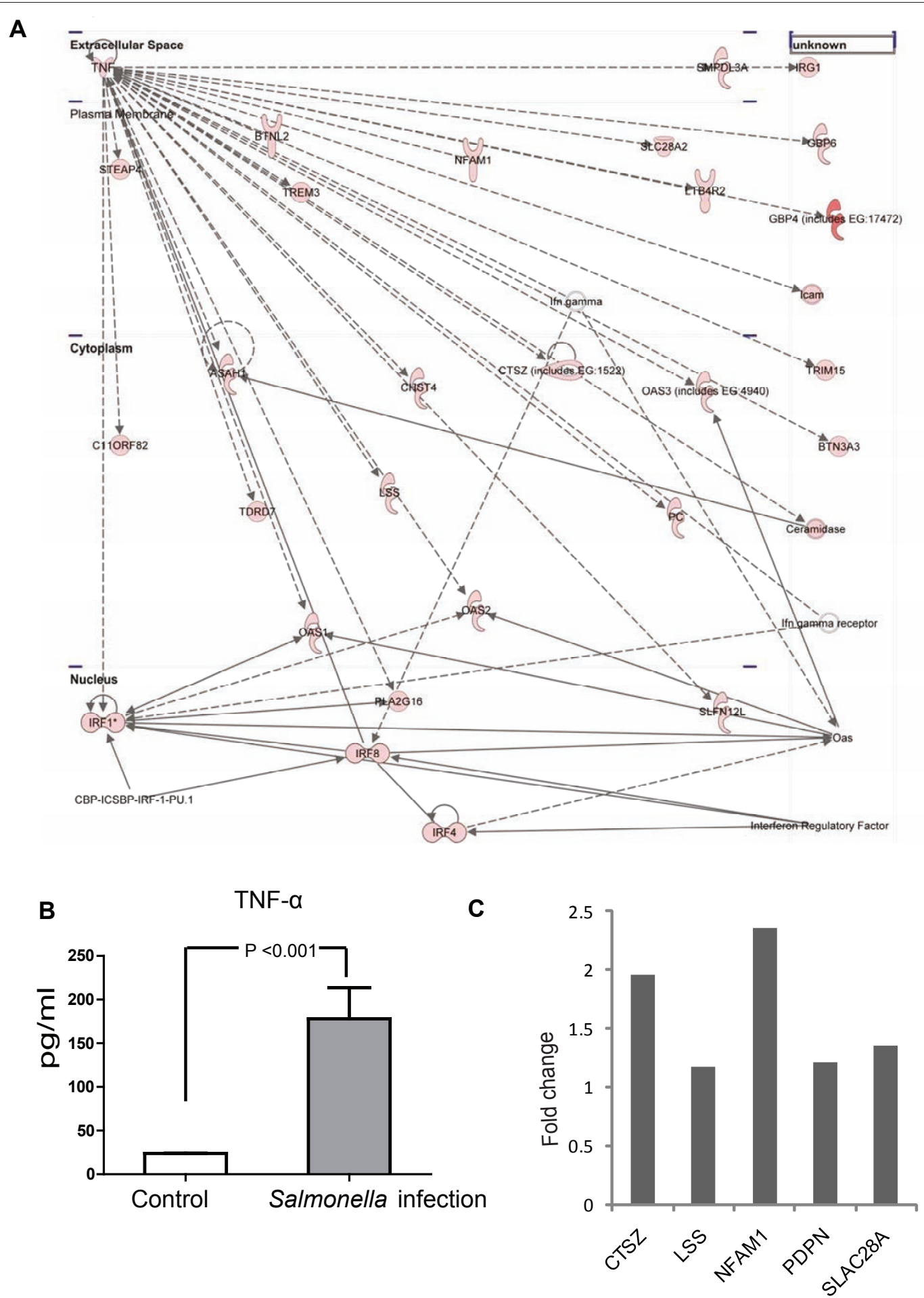

Figure 7 Ingenuity pathway analysis of the TNF- $\boldsymbol{\alpha}$ network. A. Ingenuity pathway Analysis network 3 depicting relationships among upregulated genes at the 4 day post-infection. Intensity of the red color indicates the degree of up-regulation. Edges are displayed with various labels that describe the nature of relationship between the nodes: _ represents direct relationship; ___ represents indirect relationship; $\rightarrow$ represents acts on. Nodes are displayed using various shapes that represent the functional class of the gene product same as shown Figure 6 . B. Serum TNF- $\alpha$ level in the control and the Salmonella infection group at 4 days post infection. C. Real-time PCR results for some targeted genes from the TNF- $\alpha$ network. 


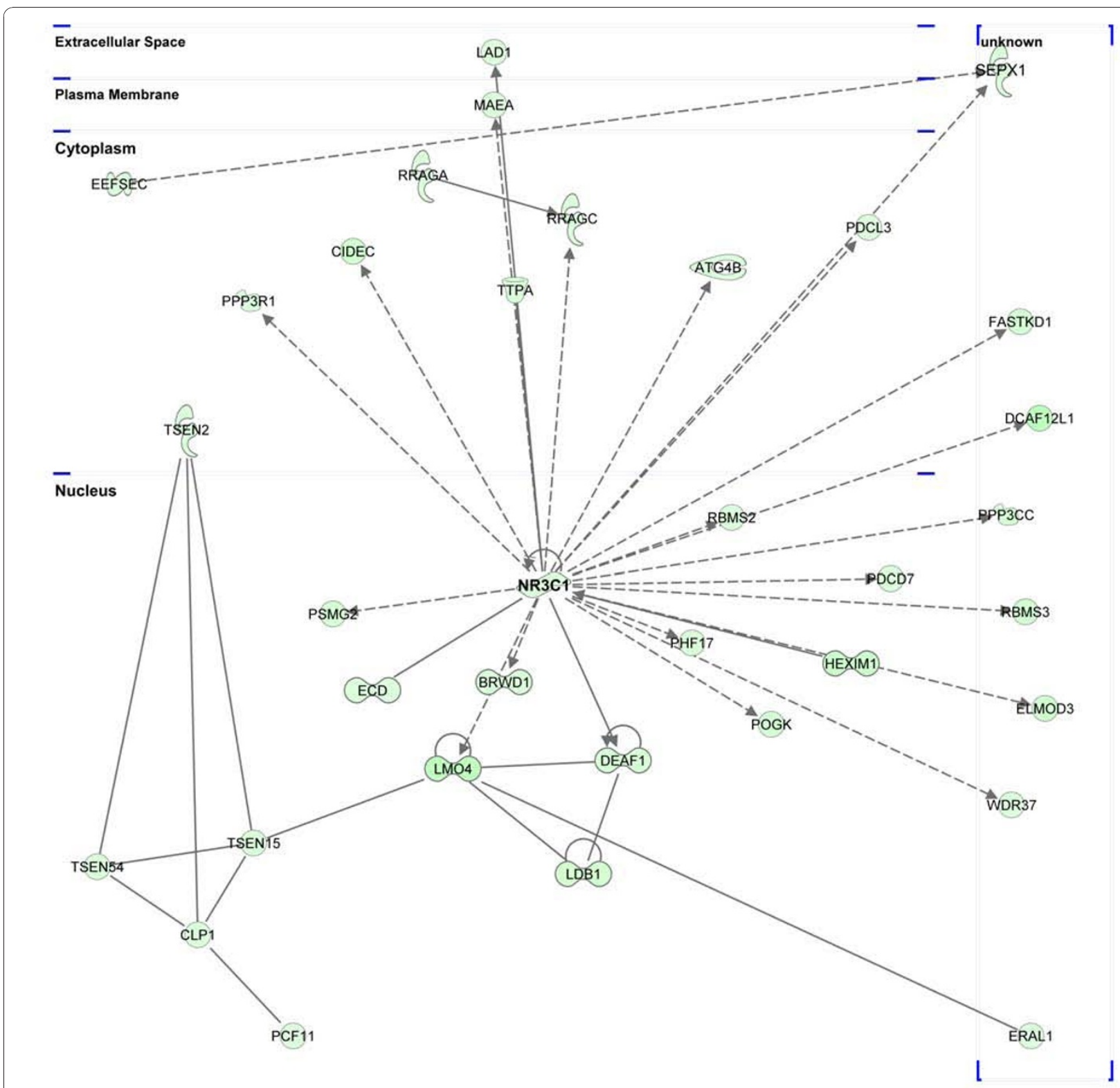

Figure 8 Ingenuity pathway analysis network 4 depicting relationships among down-regulated genes at 4 days post-infection. Intensity of the green color indicates the degree of down-regulation. Edges are displayed with various labels that describe the nature of relationship between the nodes: __ represents direct relationship; ___ represents indirect relationship; $\rightarrow$ represents acts on. Nodes are displayed using various shapes that represent the functional class of the gene product same as shown Figure 4.

cell cycle and metabolism, and protein synthesis. Pathway analysis indicated that Akt3 is involved in the following pathways, including NF- $\kappa \mathrm{B}$ pathway, EIF2 signaling, Glucocorticoid receptor signaling, eIF4 and p70S6K signaling, IL-4 signaling, Insulin receptor signaling, mTOR signaling, Jak/Stat Signaling, and VEGF signaling (Additional file 5 Table S5). In order to confirm Akt's function in Salmonella infection, we further analyzed Akts protein expression level using Western blot and immunofluorescence.
As analyzed by Western Blot (Figure 10A), Salmonella infection increased the expression of total Akt proteins compared to the control. This result is in agreement with changes at the mRNA expression level. An important step in Akt activation is its translocation from the cytosol to the plasma membrane [72]. Therefore, we tested whether Akt became activated in response to the infection of salmonella in colon mucosa. We found that the total Akt protein was located in cytosol of the normal colon. In contrast, most of the Akt was translocated 
A

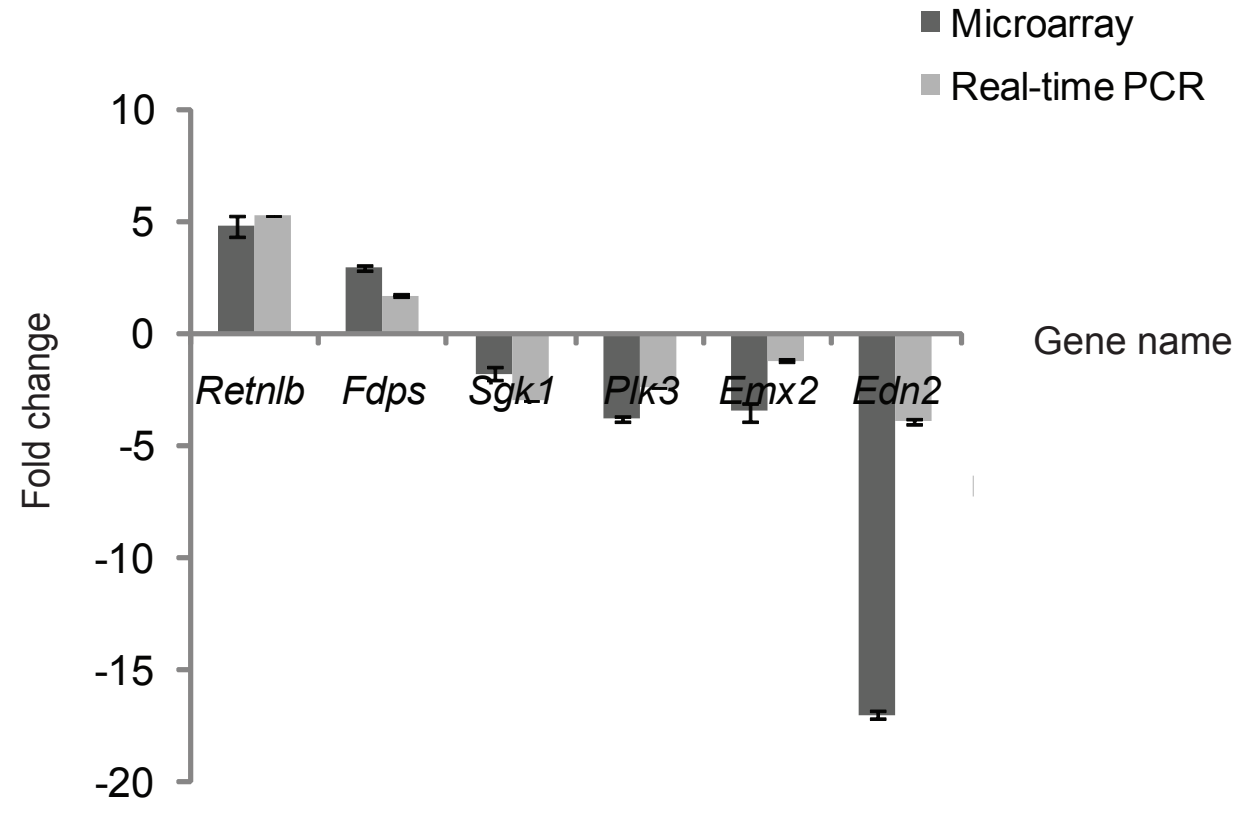

B

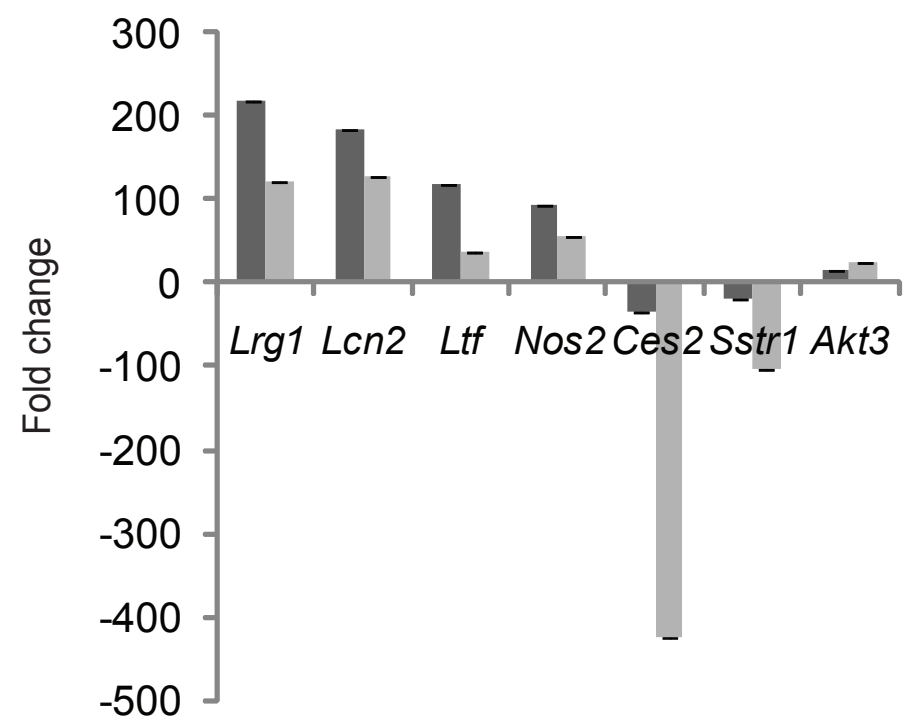

Microarray

Real-time PCR

Gene name

Figure 9 Real-time PCR analysis and microarray comparison. Transcript levels for genes of interest were determined in triplicates with control group and infection group at $8 \mathrm{hr}$ post-infection or 4 days post-infection and normalized to $\beta$-actin transcript levels. Expression level of these interest genes derived from control group were set to one. Accordingly, relative fold times at 8 hours post-infection or 4 days postinfection were normalized to control group. At each time point, error bars indicate. the standard deviation: mean \pm SEM $(n=3)$. A. real-time PCR analysis and microarray comparison at the early stage of Infection. B. real-time PCR analysis and microarray comparison at the late stage of infection.

in the plasma membrane with stronger staining in the infection group (Figure 10B bright red staining).

Histopathological analysis of Salmonella-infected and non infected tissues

To confirm the Salmonella-induced colon mucosal inflammation, we performed histopathological analysis of H\&E-stained tissue sections. As shown in Figure 10C, we did not observe inflammatory pathological changes in the infection group at 8 hours compared to the control group. Both the infection group at 8 hours and control group showed the integrity of the epithelial layer identical to that of control group. However, at 4 days post infection, H\&E-stained tissue sections revealed 
extensive pathological changes in the colon epithelium. We observed several inflammatory features, including crypt destruction and villin degradation, as well as the presence of necrotic epithelial cells (Figure 10C). In addition, immunostaining data also showed the presence of Salmonella in mouse colon 4 days post-infection (Figure 10D).

Gut homeostasis is maintained through a balance between cell damage due to the collateral effects of bacterial killing and epithelial repair by proliferation. At the late stage of infection, a series of pathways associated with inflammatory response and proliferation were identified (Table 2). Next, we examined the biological effect of Salmonella infection expression on epithelial proliferation, which is regulated by multiple pathways, including the Akt and EGF pathways. BrdU staining was performed to measure the BrdU incorporation into newly synthesized DNA. As shown in Figure 10E, BrdUpositive staining (pink) in the merged BrdU staining (red) and DAPI (blue) showed that Salmonella infection induced a more dramatic increase in epithelial cell proliferation compared to the control group without any treatment. The number of the proliferating cells per intestinal gland further showed that Salmonella increased epithelia proliferation to 12 proliferative cells per intestinal gland (Figure 10E). Our biophysiologic data is consistent with the microarray pathway analysis.

\section{Discussion}

In the current study, the Salmonella-induced pathway and network changes were mainly observed to show inflammatory inhibition and oxidative stress in mitochondria at the early stage of infection, while at the late stage of infection, the dramatic changes in thousands of gene expression are characterized.

Two networks for up-regulated genes around IFN- $\gamma$ and TNF- $\alpha$ were identified and cross-talked with some identified signaling pathways. Furthermore, a series of pathways associated with inflammatory/immune response, cell proliferation, cell apoptosis, and developmental disorder were appraised. The biochemical and pathologic data were consistent with the microarray analysis and confirmed the biological role of Salmonella in inducing inflammation and epithelium cell proliferation through the regulation of multiple signaling pathways.

\section{Salmonella infection and apoptosis}

Intestinal epithelial apoptosis is a response to bacterial infection [73]. Salmonella effector AvrA dampened the proapoptotic innate immune response to Salmonella at the mouse intestinal mucosa [74]. Our microarray data also showed that a number of genes involved in apoptosis presented Salmonella-induced expression changes, including up-regulated Caspase family members (CASP3,
CASP7, CASP8 and CASP12), Poly (ADP-ribose) polymerase family members (PARP3, PARP9, PARP12 and PARP14) and some down-regulated genes (Famim3, Stk4, Stk17 and Nalp1). Accordingly, as shown in Table 2 strong induction of apoptosis-related pathways were involved in response to Salmonella infection at 4 days, such as IL-9 (anti-apoptosis), retinoic acid mediated apoptosis (pro-apoptosis), caspase family mediated apoptosis(pro-apoptosis), and LPS-stimulated MAPK pathway (pro-apoptosis). These apparently contradictory pathways may reflect the complexity of the apoptosis process in mouse colon mucosa responded to Salmonella infection.

Salmonella effector protein $\mathrm{SigD} / \mathrm{SopB}$ protects epithelial cells from apoptosis by sustained activation of Akt $[75,76]$. Our microarray analysis along with the Western blots and immunostaining in vivo confirmed these previous researches. Overall, these results suggest that Salmonella infection in vivo increased Akt protein levels and induced Akt activation, thus regulating multiple signaling pathways.

\section{Epidermal growth factor receptor (EGFR) is involved in Salmonella infection in vivo}

EGFR is a transmembrane glycoprotein with an intrinsic tyrosine kinase. Ligand binding to the EGFR activates cell signaling. Galan et al. (1992) [77] reported that stimulation of the EGF receptor is involved in the invasion of cultured Henle-407 cells by Salmonella infection. EGFR downstream signaling proteins initiate several signal transduction cascades, principally the Stat3/Stat1, MAPK, Akt and JNK pathways, leading to DNA synthesis and cell proliferation [78]. Bertelson et al. further reported Salmonella effector SigD can activate the EGFR signaling in T84 epithelial monolayers cells through downstream signaling PI3K, and pointed out that this activation may induce different actions than what is observed in the EGFR pathway [79]. We observed the mRNA level of EGFR to be up-regulated (Additional file 22 Table S22 and Figure S1), and downstream signaling protein, such as STAT3, STAT1, AKT3 and MKK4 also showed up-regulation at 4 days post infection. Hence, our microarray data confirms previous research and extends the down-stream signaling of EGFR response to Salmonella infection and provides more comprehensive information about the EGFR pathway involved in Salmonella infection.

\section{Oxidative stress response signaling and metabolism}

NRF2-mediated oxidative stress response signaling was the most significant pathway at 4 days post infection (Table 2). This pathway involved 55 up-regulated genes and 24 down-expressed genes. Oxidative stress is caused by an imbalance between the production of reactive oxygen and the detoxification of reactive intermediates. Severe 


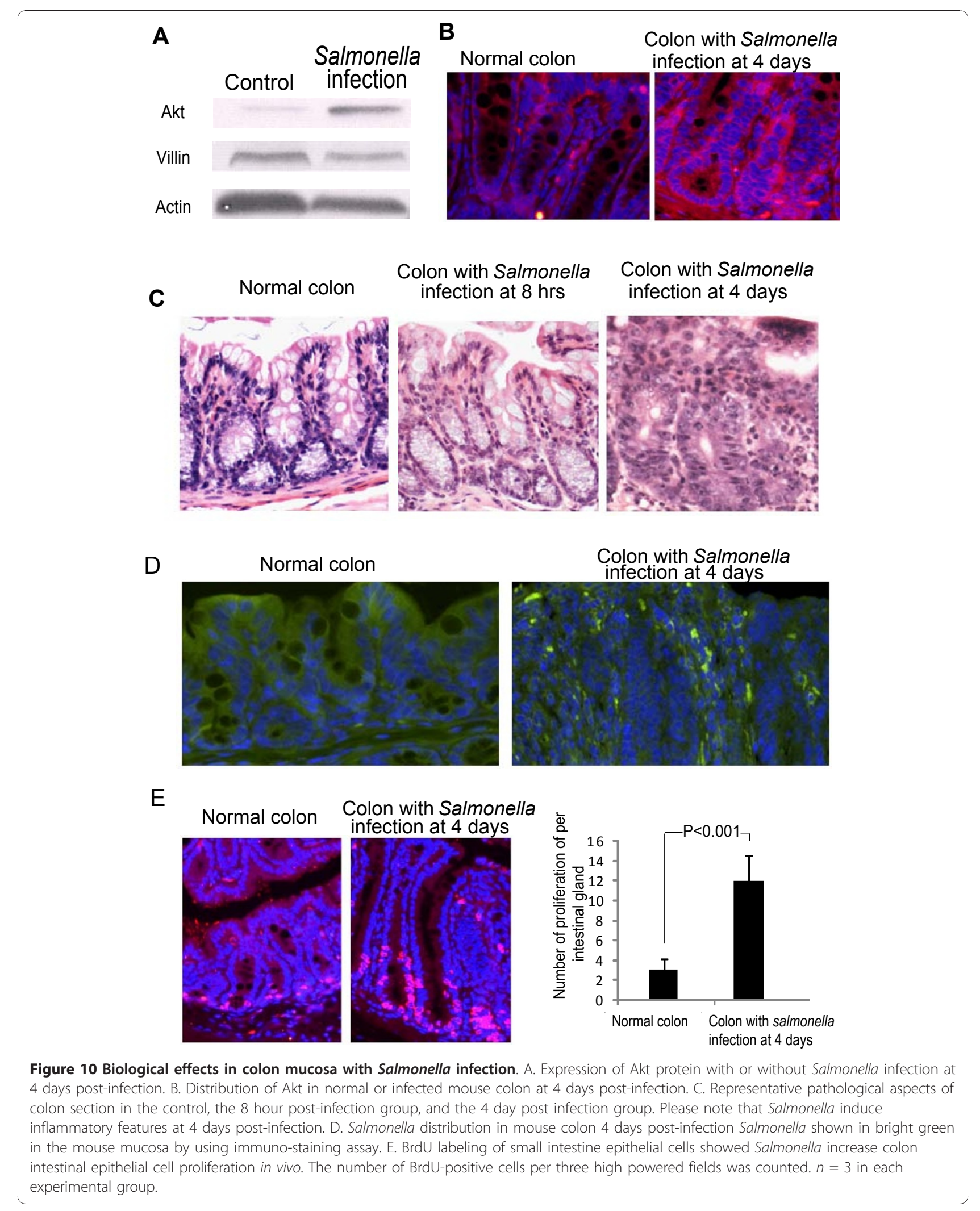


oxidative stress can trigger apoptosis and necrosis. The cellular defense response to oxidative stress includes induction of detoxifying enzymes, heat shock proteins, and antioxidant enzymes (microarray data suggested). Roland Nilsson et al found that LPS stimulation is a pivotal role for NRF-2 in orchestrating the LPS response in macrophages [80]. NRF2-mediated oxidative stress response signaling in the mouse colon intestine may be activated by Salmonella LPS. Interestingly, heat shock protein 40 (DNJ family) showed significant change in this pathway (Additional file 23 Table S23). Of the DNJ members, DNJ5 showed the most significant up-regulation. Takaya A et al (2004)[81] reported that DnaK/DnaJ chaperone machinery is involved in the bacterial invasion of intestine epithelial cells. Recently, ERdj3, an endoplasmic reticulum luminal chaperone of the Hsp40/DnaJ family, is further indentified as a target for Salmonella effector protein SlrP in HeLa cells [82]. Taken together, Salmonella effector Slrp may play a role in transmitting NRF2-mediated oxidative stress response signaling in colon mucosa.

As shown in Additional file 10, Figure S6 and Additional file 24 Table S24, all genes involved in antigen presentation pathway were up-regulated. These results are consistent with the gene expression patterns observed in the porcine lung during Salmonella infection [12]. These data illustrate that the antigen processing pathway was activated by pathogenic Salmonella infection in colon mucosa (Table 2 Figure S6).

Most genes, such as CD80, FAS, PLA2G12A, PLA2G12B, PTGS, TNFRSF1A, TNFSF1B, IIGP1, TRAF1, TIRAP, AKT3, TLR2, TLR3, TLR4, STAT1, STAT2, SLC11A1, SLC16A3, IRF9 IFIT2, and IL1B, which are known to be involved in innate/inflammatory pathway, increase their RNA expression levels significantly at 4 days post-infection. Accordingly, p38 MAPK signaling, MIF regulation of innate immunity, and LPS-stimulated MAPK signaling pathways were all activated. Most of interferon-induced protein, such as IFI35, IFI73, IFNAR2 and IFNG, were up-regulated by Salmonella. At 4 days post-infection, interferon signaling pathways were strongly affected (Table 2 Additional file 10 Figure S7 and Additional file 15 Table S15). Top functions of these genes were associated with antigen presentation, cell morphology and cell to cell signaling.

As shown Additional file 25 Table S25, 43 enzymes in the valine, leucine, and isoleucine degradation pathway were down-regulated at 4 days post-infection, including acetylCoenzyme A acyltransferase family member ( $A C A A 1$, $A C A A 2$ and $A C A A 1 B$ ), acyl-Coenzyme A dehydrogenase family member ( $A C A D 8, A C A D 10, A C A D L, A C A D M$ and $A C A D S)$, and aldehyde dehydrogenase family member (ALDH2, ALDH1A1, ALDH1A3, ALDH1A7, ALDH1B1, $A L D H 1 B 1, A L D H 3 A 2$ and $A L D H 6 A 1, A L D H 7 A 1)$. Interestingly, we observed that these enzymes are also involved in other metabolic pathways including valine, leucine, and isoleucine degradation, propanoate metabolism, fatty acid metabolism, and fatty acid elongation in mitochondria. Thus, down-regulation of these important genes may play key role in disordering embolism activities of colon mucosa.

\section{NF- $\kappa$ B}

$\mathrm{NF}-\kappa \mathrm{B}$ is a key transcriptional regulator of innate and adaptive immunity. We found that S100A1, MUC1, and TRIP6 around NF- $\kappa \mathrm{B}$ increases NF $-\kappa \mathrm{B}$ activity, but rather, BEX2, GLRX3, GPX1 and PXCARD decreases $\mathrm{NF}-\kappa \mathrm{B}$ activity. Interestingly, our microarray data showed that the expression level of BEX2, GLRX3, GPX1 and PXCARD were down-regulated at 4 days post-infection, which is different from the up-regulated mRNA level at 8 hours post infection. However, S100A1, MUC1, and TRIP6 showed a continued upregulated status at 4 days post-infection.

$I \kappa B \alpha$ and $I \kappa B z$ as inhibitory genes are activated by $\mathrm{NF}-\kappa \mathrm{B}$ in a negative feed back loop, which provides an effective mechanism for controlling the NF- $\kappa$ B activity $[83,84]$. However, we found both genes were not indentified in this network. Further microarray data also showed mRNA level of $I \kappa B \alpha$ and $\mathrm{I} \kappa \mathrm{Bz}$ remained unchanged at 8 hours post infection, but showed prominent change at 4 days post infection.

Based on the above microarray information, we speculate that NF- $\kappa \mathrm{B}$ activity undergoes early stimulation without demonstrable feedback regulation, but at with demonstrable feedback regulation at the late stage of infection. Porcine MLN during Salmonella infection also showed the similar regulation process [12].

\section{IFN- $\gamma$ and TNF- $\alpha$}

IFN- $\gamma$ is a remarkable cytokine that orchestrates many distinct cellular programs through transcriptional controlling over large numbers of genes [85]. The role of IFN- $\gamma$ is related to host defense against Salmonella infection [86]. Actually, the network analysis supports that interferon signaling was activated by Salmonella infection. We further pointed out the central role that IFN- $\gamma$ plays in mice colonic against bacterial infection (Figure S7 and Table S15).

GTPase family is clearly regulated by IFN- $\gamma$-induced genes [87], which regulate the survival of pathogens residing in phagosomes vacuoles. We observed that GTPase family members, such as GViN1, Gbp8, Gbp5, IIGP1 and IRGM, are directly targeted by IFN- $\gamma$ (Figure 6A). The data correlate with the observation in rat colonic cells infected with Salmonella $[58,88]$. In particular, IIGP1 was found to be highly up-regulated in our microarray data (90 fold times). Uthaiah RC et al (2003) [89] also reported that recombinant IIGP1 showed cooperative enzymatic activity and GTP-dependent multimerization. 
TNF- $\alpha$ encodes a multifunctional proinflammatory cytokine that belongs to the tumor necrosis factor (TNF) superfamily. This cytokine is involved in the regulation of a wide spectrum of biological processes including cell proliferation, differentiation, apoptosis and lipid metabolism [90,91]. As expected, the genes in this network are associated with TNF function. Interestingly, we observed GBP4 and GBP6 as IFN- $\gamma$ induced genes (Figure 6A) that are also involved in TNF- $\alpha$ network. GBP4 showed highly up-regulated in microarray data. Degrandi et al. (2007)[92] reported mouse TNF- $\alpha$ protein increases expression of mouse GBP4 mRNA in ANA-1 cells, but we did not find other reports showing that GBP6 were TNF- $\alpha$-induced genes. Therefore, further experiment is needed to establish whether this gene is up-regulated by TNF- $\alpha$ in mouse colonic mucosa after Salmonella infection.

Clare et al. (2003) used ICAM (-/-) knockout mice to demonstrate that ICAM-1 plays a critical role during the rechallenge of immunized mice with virulent Salmonella [93]. Our network and microarray data also confirmed that the intracellular adhesion molecule ICAM was induced by TNF- $\alpha$. We further observed CTSZ as an antigen presentation molecule is also up-regulated. Thus, the network analysis is consistent with the previous experiment results: production of TNF- $\alpha$ in the intestinal tract following $S$. typhimurium infection and the observation that early pathology induced by Salmonella infection of the gastrointestinal tract is mediated by immune mechanisms [94].

Overall, the number of connections among the molecules other than TNF- $\alpha$ or IFN- $\gamma$ is quite limited (Figure 6A and Figure 7A). Most of genes are targeted directly by TNF- $\alpha$ or IFN $-\gamma$, which are very different from that of NF- $\kappa$ B network shown in Figure 4. Hence, these TNF- $\alpha$ or IFN- $\gamma$ networks further reflect the pleiotropic action of proinflammatory cytokine involved in host defense against $\mathrm{Sal}$ monella infection by regulating extensive biological process.

\section{T helper 2 (Th2) immune response}

Both Interleukin-4 (IL-4) and Interleukin-9 (IL-9) are multifunctional cytokine secreted by T helper 2 (Th2) lymphocytes. IL-9 stimulates the growth and proliferation of $\mathrm{T}$ cells, and promotes the proliferation and differentiation of mast cells and hematopoietic progenitors $[95,96]$. IL-4 plays a critical role in the regulation of immune responses [97] and the pathogenesis of inflammatory bowel disease $[98,99]$.

Previous research study reveled that IL-9 receptor and IL-4 receptor ligation results in auto and/or transphosphorylation of Janus kinases 1 and 3 (JAK1 and JAK3) phosphorylation of the receptor, and activation of the pathways involved in IL-9 signaling and IL-4 signaling
$[100,101]$. These pathways include signal transducer and activator of transcription 1, 3, 5 and 6 (STAT1, STAT3, and STAT5 and STAT6), Insulin receptor substrate 1 and 2 (IRS-1 and IRS-2)/Phosphoinositide-3-kinase (PI3K regulatory subunit) and Extracellular signal regulated kinases 1 and 2 (ERK1/2) [102-104].

We observed the mRNA level of IL-9 receptor (IL-2 $R$ ) and IL-4 receptor ( $I L-2 R, I L-4 R I L-13 R)$ are up-regulated and that downstream signaling protein, such as JAK2 JAK3, STAT1, STAT2, STAT3, IRS1, SOCS1 and SOCS3 showed up-regulation at 4 days post infection (Figure S2, Figure S8, Additional file 26 Table S26, and Additional file 27 Table S27). Dumoutier et al. reported that STAT1 and STAT3, activated by IL-9, then upregulate the transcription of IL-3 and IL-22, which are involve in the generation of inflammatory and allergic responses [95]. Accordingly, we also observed that Interleukin-3 and 22 were up-regulated in mouse colon mucosa with Salmonella infection at four days (Additional file 2 Table S2). IL-4 is produced in response to IL-18 or IL-33 stimulation from mouse basophils [105]. We also found IL-18b and IL-33 to be up-regulated (Additional file 2 Table S2). Overall, these data illustrate that the IL-4 and IL-9 signaling pathway associated with TH2 immune response was activated by pathogenic Salmonella infection in colon mucosa.

Recent advances have called attention to the the involvement of allergen- and parasite product-mediated activation of epithelial cells, basophils and dendritic cells and the functions of the cytokines IL-4, IL-25, IL-33 in the initiation and amplification of TH2-type immune responses in vivo [106,107].

Cytokines play a key role in IBD that determine $\mathrm{T}$ cell differentiation of Th1, Th2, T regulatory and newly described Th17 cells [99]. Hence, IL-4 and IL-9 signaling pathway activated in mouse mucosa with Salmonella infection provides more comprehensive information about how the Th2 immune system interplays with signaling transducers in colon mucosal inflammation.

In Drosophila, the Janus kinases-signal transducers and activators of transcription (Jak-Stat) pathway plays an important role in hematopoiesis, stress response, stem cell proliferation, and antiviral immunity in intestine $[87,108-110]$. Interestingly, mouse microarray data showed Jak2, Stat1 and Stat3 as vital proteins in this pathway and were up-regulated at the 4 days post-infection. The mouse colon mucosal complex system is different from Drosophila gut, stat proteins are intracellular effector molecules of cytokine-modulated signaling in mammalian immune system [111]. Further research is needed to validate our analysis and how JAK-Stat signaling regulates the host response during Salmonella infection.

However, even if we confirmed the coherence of our microarray data by other molecular biology approaches, 
this study has limitations: transcriptional changes not representing the changes at the post-transcriptional level, posttransductional behavior of the differentially expressed genes, and statistical error. For example, our published data showed that Salmonella effector AvrA can activate the beta-catenin pathway through deubquitination [44]. However, this activated pathway was not revealed in this analysis. Further studies combining genomic and proteomic are necessary to find out more details of host cell interplay with Salmonella. Moreover, the colon mucosa tissue samples used in this experiment contained several cell types. Diverse pathways may be activated in different cell types, not necessarily within one kind of cells. Future research on structured information and pathways occurring in individual kind of cells is required.

\section{Conclusion}

In this current study, we are the first to show a bioinformatics strategy to investigate global pathway and network of host responses to Salmonella infection in mouse colon mucosa at the early and chronic infection stages. We found that Salmonella infection caused dramatic changes in gene expression of colon mucosa, which further leads to a sequence of cellular events that involve activating and blocking signaling modulation responses in colon mucosa. IFN- $\gamma$ - and TNF- $\alpha$ receptormediated signaling cascades stimulated the expression of IFN- $\gamma$ - and TNF- $\alpha$-inducible genes. We not only confirmed IFN- $\gamma$ and TNF- $\alpha$ secretion in mice infected with Salmonella, but also observed that many of the genes regulated by cytokine IFN- $\gamma$ and TNF- $\alpha$ contributed to the modulation of cell proliferation and growth, apoptosis, and developmental disorders.

Moreover, we observed a general repression process of metabolic pathways, specifically shown in the amino acid metabolic and lipid metabolic related pathways. These changed genes are not commonly altered in a cytokine-dependent manner. We speculate that the inhibited metabolic pathways in host cells combined with the relevant signaling pathways presumably increase the opportunities of bacteria growth in host cells, and can further lead to metabolic, infectious, and inflammatory diseases in the intestine.

Overall, our data provide not only new networks between the genes for understanding the biologic properties of Salmonella infection in mouse colon mucosa, but also provide useful pathway maps for future understanding of the pathology of inflammatory bowel diseases, inflammation associated colon tumorigensis and other diseases. It will help us to develop a new protocol for anti-bacterial infection, risk assessment, and prevention of the intestinal illness and other chronic diseases.

\section{Acknowledgements and Funding}

We thank Dr. Constance D. Baldwin and Julia Militar at the University of Rochester for critical revising and editing of this manuscript, $\mathrm{Xi}$ Emma Li for her excellent technical support, and Jody Bown and Stephen L. Willie for helpful suggestion on microarray software. This work was supported by the National Institutes of Health (DK075386-0251, R03DK089010-01), the American Cancer Society (RSG-09-075-01-MBC), and the IDEAL award from the New York State's Empire State Stem Cell Board (N09G-279) to Jun Sun.

\section{Additional material}

Additional file 1: Primer sequence for qRT-PCR. Listing all primer
sequences used in qRT-PCR (PDF file). PCR data were shown in Figure
$6 C, 7 C$, and Figure 9.

Additional file 2: The list of differentially expressed genes between the control and $\mathbf{8}$ hours post-infection groups. Listing differentially expressed genes (fold times $\geq 1.2 ; P<0.05$ ) at 8 hours post-infection comparing with the control group without Salmonella infection.

Additional file 3: The list of differentially expressed genes between the control and at $\mathbf{4}$ days post- infection groups. At 4 days postinfection, differentially expressed genes are listed in Table S3.

Additional file 4: The list of differentially expressed genes between the 8 hours and 4 days post- SL1344 infection. Identify genes that were expressed differentially during two time course.

Additional file 5: All pathways involved in colon mucosa 8 hours post-SL1344 infection. List pathways involved in colon mucosa with Salmonella infection at 8 hours.

Additional file 6: The gene list for Network 1, NF-kappaB. List genes interact directly with NF-kappaB transcription factor.

Additional file 7: Networks of interacting up-regulated genes at $\mathbf{8}$ hours post-infection. Identify 14 highly significant networks of potentially interacting up-regulated genes at 8 hours post-infection group.

Additional file 8: Down-regulated genes 8 hours post-infection Identify 16 highly significant networks of potentially interacting downregulated genes and did not identify a network with center regulation.

Additional file 9: All signaling pathways involved in colon mucosa with Salmonella infection at $\mathbf{4}$ days. List canonical pathways involving signaling associated with differential genes at 4 days post infection.

Additional file 10: Canonical pathways changed by SL1344 infection. Figures for representative pathways involving signaling associated with Salmonella infection. Figure S1 EGF signaling; Figure S2 IL-9; Figure S3: Metabolic pathways; Figure S4: Top canonical signaling. Figure S5: co-regulated pathway between 8 hours and 4 days postinfection. Figure S6: Antigen presentation pathway; Figure S7: Interferon signaling; and Figure S8: IL-4 signaling.

Additional file 11: All metabolism pathways involved in colon mucosa with Salmonella infection at $\mathbf{4}$ days. All metabolism pathways involved in colon mucosa with Salmonella infection at 4 days.

Additional file 12: All metabolic pathways involved in colon mucosa with these differentially expression gene between $8 \mathrm{hr}$ postinfection and 4 day post-infection. List the metabolism pathways involved in mucosa infection with these differentially expression gene between $8 \mathrm{hr}$ post-infection and 4 day post-infection (fold times $\geq 1.2$ times, p-value < 0.05).

Additional file 13: Networks of interacting genes from amongst the up-regulated genes at 4 days post-infection. Identify highly significant networks of interacting genes from amongst the up-regulated genes at 4 days post-infection. 
Additional file 14: Networks of interacting genes from amongst the down-regulated genes at $\mathbf{4}$ days post-infection. Identify highly significant networks of interacting genes from amongst the downregulated genes at 4 days post-infection.

Additional file 15: The gene list for Network 2. Network 2 presents IFN- $\gamma$ in central positions and consists of 35 DEGs genes that are all regulated positively by IFN- $\gamma$.

Additional file 16: The gene list for Network 3. The network TNF- $\alpha$ in central positions and consists of genes that are all positively regulated by TNF- $\alpha$.

Additional file 17: The gene list for Network 4. The network 4 in central positions and consists genes that are all positively regulated by NR3C 1 .

Additional file 18: Common up-regulated genes function in both early stage and late stage of infection. Identity commonly upregulated in response to Salmonella infection at the early and late stage of infection.

Additional file 19: Functional categories associated with common up-regulated genes. Identify the top functional categories associated with these common up-regulated genes.

Additional file 20: Common down-regulated genes function in both early stage and late stage of infection. Identity commonly downregulated in response to Salmonella infection at the early and late stage of infection.

Additional file 21: Functional categories associated with common down-regulated genes. Identify the top functional categories associated with these common down-regulated genes.

Additional file 22: The gene list for EGFR signaling pathways at 4 days of post-infection. EGFR and downstream signaling proteins are involved in Salmonella infection.

Additional file 23: The gene list for NRF2-mediated oxidative stress response signaling at 4 days of post-infection.

Additional file 24: Antigen presentation pathway were up-

regulated. the antigen processing pathway was activated by pathogenic Salmonella infection in colon mucosa.

Additional file 25: 43 enzymes down-regulated at 4 days postinfection. 43 enzymes in the valine, leucine, and isoleucine degradation pathway were down-regulated at 4 days post-infection, including acetylCoenzyme A acyltransferase family member

Additional file 26: The gene list for IL-4 signaling pathway at $\mathbf{4}$ days of post-infection. Identify genes associated with IL-4 at 4 days postinfection.

Additional file 27: The gene list for IL-9 signaling pathway at 4 days of post-infection. Identify genes associated with IL-9 at 4 days postinfection.

\section{Abbreviations}

DEG: Differentially expression gene; EGF: Epidermal growth factor; EGFR: Epidermal growth factor receptor; ERK: extracellular signal-regulated kinases; IBD: inflammatory bowel diseases; ICAM: intercellular adhesion molecule; IFNG: Interferon-gamma; IPA: Ingenuity Pathways Analysis; IL-4: Interleukin-4; IL-9: Interleukin-9; JAK-STAT: Janus kinases- Signal Transducers and Activators of Transcription protein; JNK: JUN-NH 2 -terminal kinase; LPS:

Lipopolysaccharides; MAPK: mitogen-activated protein kinase; MTOR: mammalian target of rapamycin; NF- $\kappa \mathrm{B}$ : Nuclear factor $\kappa \mathrm{B}$; PXR: pregnane $\times$ receptor, or NR112 (nuclear receptor subfamily 1, group I, member 2); RXR: Retinoid $\times$ receptor; TNF: Tumor necrosis factor; TTSS: Type Three Secretion System; STAT: Signal transducer and activator of transcription.

\section{Author details}

'Department of Medicine, Gastroenterology \& Hepatology Division, University of Rochester, 601 Elmwood Avenue, Rochester, NY 14642, USA. ${ }^{2}$ Department of Biostatistics and Computational Biology, University of Rochester, 601 Elmwood Avenue, Rochester, NY 14642, USA. ${ }^{3}$ Department of
Microbiology and Immunology, University of Rochester, 601 Elmwood Avenue, Rochester, NY 14642, USA. ${ }^{4}$ Wilmot Cancer Center, University of Rochester, 601 Elmwood Avenue, Rochester, NY 14642, USA.

\section{Authors' contributions}

$\mathrm{XL}$ : participated in experimental design, animal experiment, preparation of RNA sample, real-time PCR, western blot and immunofluorescence analysis, acquisition of data, analysis and interpretation of data, carried out bioinformatics analysis, and drafted table, figure and the manuscript. RL: participated in experimental design, analysis and interpretation of data, real-time PCR analysis, drafted tables and figures, and carried out animal experiments

YX: participated in interpretation of data, performed statistical analysis, and edited the manuscript for important intellectual content.

JS: participated in study concept and design, acquisition of data, analysis and interpretation of data, material support, writing and critical revision of the manuscript for critical intellectual content, obtained funding, and supervised study.

All authors read and approved the final manuscript.

Received: 22 June 2010 Accepted: 20 December 2010

Published: 20 December 2010

\section{References}

1. Herikstad H, Motarjemi Y, Tauxe RV: Salmonella surveillance: a global survey of public health serotyping. Epidemiol Infect 2002, 129(1):1-8.

2. Mead PS, Slutsker L, Dietz V, McCaig LF, Bresee JS, Shapiro C, Griffin PM, Tauxe RV: Food-related illness and death in the United States. Emerg Infect Dis 1999, 5(5):607-625.

3. Darwin KH, Miller VL: Molecular basis of the interaction of Salmonella with the intestinal mucosa. Clinical microbiology reviews 1999, 12(3):405-428.

4. Brown NF, Vallance BA, Coombes BK, Valdez Y, Coburn BA, Finlay BB: Salmonella pathogenicity island 2 is expressed prior to penetrating the intestine. PLoS Pathog 2005, 1(3):e32.

5. Du F, Galan JE: Selective inhibition of type III secretion activated signaling by the Salmonella effector AvrA. PLoS Pathog 2009, 5(9):e1000595.

6. Gradel KO, Nielsen HL, Schonheyder HC, Ejlertsen T, Kristensen B, Nielsen H: Increased short- and long-term risk of inflammatory bowel disease after salmonella or campylobacter gastroenteritis. Gastroenterology 2009, 137(2):495-501.

7. Kumar S: Infection as a risk factor for gallbladder cancer. J Surg Oncol 2006, 93(8):633-639.

8. Mager DL: Bacteria and cancer: cause, coincidence or cure? A review. J Transl Med 2006, 4:14.

9. Arrach N, Zhao M, Porwollik S, Hoffman RM, McClelland M: Salmonella promoters preferentially activated inside tumors. Cancer Res 2008 68(12):4827-4832.

10. Zhao M, Yang M, Li XM, Jiang P, Baranov E, Li S, Xu M, Penman S, Hoffman RM: Tumor-targeting bacterial therapy with amino acid auxotrophs of GFP-expressing Salmonella typhimurium. Proceedings of the National Academy of Sciences of the United States of America 2005, 102(3):755-760.

11. Zhao M, Geller J, Ma H, Yang M, Penman S, Hoffman RM: Monotherapy with a tumor-targeting mutant of Salmonella typhimurium cures orthotopic metastatic mouse models of human prostate cancer. Proc Natl Acad Sci USA 2007, 104(24):10170-10174.

12. Wang Y, Qu L, Uthe JJ, Bearson SM, Kuhar D, Lunney JK, Couture OP, Nettleton D, Dekkers JC, Tuggle CK: Global transcriptional response of porcine mesenteric lymph nodes to Salmonella enterica serovar Typhimurium. Genomics 2007, 90(1):72-84

13. Detweiler CS, Cunanan DB, Falkow S: Host microarray analysis reveals a role for the Salmonella response regulator phoP in human macrophage cell death. Proc Natl Acad Sci USA 2001, 98(10):5850-5855.

14. van Hemert S, Hoekman AJ, Smits MA, Rebel JM: Early host gene expression responses to a Salmonella infection in the intestine of chickens with different genetic background examined with cDNA and oligonucleotide microarrays. Comp Biochem Physiol Part D Genomics Proteomics 2006, 1(3):292-299.

15. van Hemert S, Hoekman AJ, Smits MA, Rebel JM: Gene expression responses to a Salmonella infection in the chicken intestine differ between lines. Vet Immunol Immunopathol 2006, 114(3-4):247-258. 
16. Mastroeni P, Sheppard M: Salmonella infections in the mouse model: host resistance factors and in vivo dynamics of bacterial spread and distribution in the tissues. Microbes Infect 2004, 6(4):398-405.

17. Barthel M, Hapfelmeier S, Quintanilla-Martinez L, Kremer M, Rohde M, Hogardt M, Pfeffer K, Russmann H, Hardt WD: Pretreatment of mice with streptomycin provides a Salmonella enterica serovar Typhimurium colitis model that allows analysis of both pathogen and host. Infection and immunity 2003, 71(5):2839-2858.

18. Wang Y, Couture OP, Qu L, Uthe JJ, Bearson SM, Kuhar D, Lunney JK, Nettleton D, Dekkers JC, Tuggle CK: Analysis of porcine transcriptional response to Salmonella enterica serovar Choleraesuis suggests novel targets of NFkappaB are activated in the mesenteric lymph node. BMC Genomics 2008, 9:437.

19. Karavolos MH, Spencer H, Bulmer DM, Thompson A, Winzer $\mathrm{K}_{\text {, }}$ Williams P, Hinton JC, Khan CM: Adrenaline modulates the global transcriptional profile of Salmonella revealing a role in the antimicrobial peptide and oxidative stress resistance responses. BMC Genomics 2008, 9:458.

20. Chiang HI, Swaggerty CL, Kogut MH, Dowd SE, Li X, Pevzner IY, Zhou H: Gene expression profiling in chicken heterophils with Salmonella enteritidis stimulation using a chicken $44 \mathrm{~K}$ Agilent microarray. BMC Genomics 2008, 9:526.

21. Abreu MT: Immunologic regulation of toll-like receptors in gut epithelium. Curr Opin Gastroenterol 2003, 19(6):559-564.

22. Abreu MT: Toll-like receptor signalling in the intestinal epithelium: how bacterial recognition shapes intestinal function. Nat Rev Immunol 10(2):131-144.

23. Becker SM, Cho KN, Guo X, Fendig K, Oosman MN, Whitehead R, Cohn SM, Houpt ER: Epithelial cell apoptosis facilitates Entamoeba histolytica infection in the gut. Am J Pathol 176(3):1316-1322.

24. Fu Z, Kim J, Vidrich A, Sturgill TW, Cohn SM: Intestinal Cell Kinase, a MAP Kinase-Related Kinase, Regulates Proliferation and G1 Cell Cycle Progression of Intestinal Epithelial Cells. Am J Physiol Gastrointest Liver Physiol 2009, 297(4):G632-40.

25. Keely $S$, Glover $L E$, Weissmueller $T$, MacManus $C F$, Fillon $S$, Fennimore $B$, Colgan SP: Hypoxia-inducible factor-dependent regulation of plateletactivating factor receptor as a route for gram-positive bacterial translocation across epithelia. Mol Biol Cell 2010, 21(4):538-546.

26. Jilling T, Simon D, Lu J, Meng FJ, Li D, Schy R, Thomson RB, Soliman A, Arditi M, Caplan MS: The roles of bacteria and TLR4 in rat and murine models of necrotizing enterocolitis. J Immunol 2006, 177(5):3273-3282.

27. Jilling T, Lu J, Jackson M, Caplan MS: Intestinal epithelial apoptosis initiates gross bowel necrosis in an experimental rat model of neonatal necrotizing enterocolitis. Pediatr Res 2004, 55(4):622-629.

28. Neish AS: Molecular aspects of intestinal epithelial cell-bacterial interactions that determine the development of intestinal inflammation. Inflamm Bowel Dis 2004, 10(2):159-168.

29. Neish AS: Microbes in gastrointestinal health and disease. Gastroenterology 2009, 136(1):65-80.

30. Si-Tahar M, Merlin D, Sitaraman S, Madara JL: Constitutive and regulated secretion of secretory leukocyte proteinase inhibitor by human intestinal epithelial cells. Gastroenterology 2000, 118(6):1061-1071.

31. Kolachala V, Ruble B, Vijay-Kumar M, Wang L, Mwangi S, Figler H, Figler R, Srinivasan S, Gewirtz A, Linden J, et al: Blockade of adenosine A2B receptors ameliorates murine colitis. Br J Pharmacol 2008, 155(1):127-137.

32. Hardt WD, Galan JE: A secreted Salmonella protein with homology to an avirulence determinant of plant pathogenic bacteria. Proc Natl Acad Sci USA 1997, 94(18):9887-9892.

33. Sun J, Hobert ME, Rao AS, Neish AS, Madara JL: Bacterial activation of beta-catenin signaling in human epithelia. Am J Physiol Gastrointest Liver Physiol 2004, 287(1):G220-227.

34. McCormick BA, Colgan SP, Delp-Archer C, Miller SI, Madara JL: Salmonella typhimurium attachment to human intestinal epithelial monolayers: transcellular signalling to subepithelial neutrophils. J Cell Biol 1993, 123(4):895-907.

35. Strath J, Georgopoulos L, Kellam P, Blair GE: Identification of genes differentially expressed as result of adenovirus type 5 - and adenovirus type 12-transformation. BMC Genomics 2009, 10:67.

36. Jickling GC, Zhan X, Ander BP, Turner RJ, Stamova B, Xu H, Tian Y, Liu D, Davis RR, Lapchak PA, et al: Genome response to tissue plasminogen activator in experimental ischemic stroke. BMC Genomics 11:254.
37. Storey JD, Tibshirani R: Statistical significance for genomewide studies. Proc Natl Acad Sci USA 2003, 100(16):9440-9445.

38. Tusher VG, Tibshirani R, Chu G: Significance analysis of microarrays applied to the ionizing radiation response. Proc Natl Acad Sci USA 2001, 98(9):5116-5121.

39. Li CJ, Li RW, Wang YH, Elsasser TH: Pathway analysis identifies perturbation of genetic networks induced by butyrate in a bovine kidney epithelial cell line. Funct Integr Genomics 2007, 7(3):193-205.

40. Lagoa CE, Bartels J, Baratt A, Tseng G, Clermont G, Fink MP, Billiar TR, Vodovotz $Y$ : The role of initial trauma in the host's response to injury and hemorrhage: insights from a correlation of mathematical simulations and hepatic transcriptomic analysis. Shock 2006, 26(6):592-600.

41. Calvano SE, Xiao W, Richards DR, Felciano RM, Baker HV, Cho RJ, Chen RO, Brownstein BH, Cobb JP, Tschoeke SK, et al: A network-based analysis of systemic inflammation in humans. Nature 2005, 437(7061):1032-1037.

42. Livak KJ, Schmittgen TD: Analysis of relative gene expression data using real-time quantitative PCR and the 2(-Delta Delta $C(T))$ Method. Methods 2001, 25(4):402-408.

43. Liao AP, Petrof EO, Kuppireddi S, Zhao Y, Xia Y, Claud EC, Sun J: Salmonella type III effector AvrA stabilizes cell tight junctions to inhibit inflammation in intestinal epithelial cells. PLOS ONE 2008, 3(6):e2369

44. Ye Z, Petrof EO, Boone D, Claud EC, Sun J: Salmonella effector AvrA regulation of colonic epithelial cell inflammation by deubiquitination. Am J Pathol 2007, 171(3):882-892

45. Lu R, Wu S, Liu X, Xia Y, Zhang YG, Sun J: Chronic effects of a Salmonella type III secretion effector protein AvrA in vivo. PLOS ONE 5(5):e10505.

46. Duan Y, Liao AP, Kuppireddi S, Ye Z, Ciancio MJ, Sun J: beta-Catenin activity negatively regulates bacteria-induced inflammation. Lab Invest 2007, 87(6):613-624.

47. Wu S, Ye Z, Liu X, Zhao Y, Xia Y, Steiner A, Petrof EO, Claud EC, Sun J: Salmonella typhimurium infection increases p53 acetylation in intestinal epithelial cells. Am J Physiol Gastrointest Liver Physiol 298(5):G784-794.

48. Liu X, Lu R, Wu S, Sun J: Salmonella regulation of intestinal stem cells through the Wnt/beta-catenin pathway. FEBS Lett 584(5):911-916.

49. Wu S, Liao AP, Xia Y, Li YC, Li JD, Sartor RB, Sun J: Vitamin D receptor negatively regulates bacterial-stimulated NF-kappaB activity in intestine. Am J Pathol 177(2):686-697.

50. He W, Wang ML, Jiang HQ, Steppan CM, Shin ME, Thurnheer MC, Cebra JJ, Lazar MA, Wu GD: Bacterial colonization leads to the colonic secretion of RELMbeta/FIZZ2, a novel goblet cell-specific protein. Gastroenterology 2003, 125(5):1388-1397.

51. Young CL, Feierstein A, Southwick FS: Calcium regulation of actin filament capping and monomer binding by macrophage capping protein. J Biol Chem 1994, 269(19):13997-14002.

52. Hayward RD, Koronakis V: Direct nucleation and bundling of actin by the SipC protein of invasive Salmonella. EMBO J 1999, 18(18):4926-4934.

53. Zhou D, Mooseker MS, Galan JE: Role of the $\mathrm{S}$. typhimurium actin-binding protein SipA in bacterial internalization. Science 1999, 283(5410):2092-2095

54. Scherer CA, Cooper E, Miller SI: The Salmonella type III secretion translocon protein $\mathrm{SspC}$ is inserted into the epithelial cell plasma membrane upon infection. Mol Microbiol 2000, 37(5):1133-1145.

55. Unsal-Kacmaz K, Chastain PD, Ou PP, Minoo P, Cordeiro-Stone M, Sancar A, Kaufmann WK: The human Tim/Tipin complex coordinates an Intra-S checkpoint response to UV that slows replication fork displacement. $\mathrm{Mol}$ Cell Biol 2007, 27(8):3131-3142.

56. Errico A, Costanzo V, Hunt T: Tipin is required for stalled replication forks to resume DNA replication after removal of aphidicolin in Xenopus egg extracts. Proc Natl Acad Sci USA 2007, 104(38):14929-14934.

57. Wu S, Ye Z, Liu X, Zhao Y, Xia Y, Steiner A, Petrof EO, Claud EC, Sun J: Salmonella typhimurium infection increases p53 acetylation in intestinal epithelial cells. Am J Physiol Gastrointest Liver Physiol 2010, 298(5):G784-794.

58. Rodenburg W, Keijer J, Kramer E, Roosing S, Vink C, Katan MB, van der Meer R, Bovee-Oudenhoven IM: Salmonella induces prominent gene expression in the rat colon. BMC Microbiol 2007, 7:84.

59. Lewin MJ: The somatostatin receptor in the GI tract. Annu Rev Physiol 1992, 54:455-468.

60. Rossowski WJ, Gu ZF, Akarca US, Jensen RT, Coy DH: Characterization of somatostatin receptor subtypes controlling rat gastric acid and pancreatic amylase release. Peptides 1994, 15(8):1421-1424. 
61. Bousquet C, Puente E, Buscail L, Vaysse N, Susini C: Antiproliferative effect of somatostatin and analogs. Chemotherapy 2001, 47(Suppl 2):30-39.

62. van Hemert S, Hoekman AJ, Smits MA, Rebel JM: Immunological and gene expression responses to a Salmonella infection in the chicken intestine. Vet Res 2007, 38(1):51-63.

63. Vreugdenhil GR, Wijnands PG, Netea MG, van der Meer JW, Melchers WJ, Galama JM: Enterovirus-induced production of pro-inflammatory and Thelper cytokines by human leukocytes. Cytokine 2000, 12(12):1793-1796.

64. Bertilsson PM, Olsson P, Magnusson KE: Cytokines influence mRNA expression of cytochrome P450 3A4 and MDRI in intestinal cells. J Pharm Sci 2001, 90(5):638-646

65. Gewirtz AT, Rao AS, Simon PO, Merlin D, Carnes D, Madara JL, Neish AS: Salmonella typhimurium induces epithelial IL-8 expression via $\mathrm{Ca}(2$ +)-mediated activation of the NF-kappaB pathway. J Clin Invest 2000, 105(1):79-92.

66. Hobbie S, Chen LM, Davis RJ, Galan JE: Involvement of mitogen-activated protein kinase pathways in the nuclear responses and cytokine production induced by Salmonella typhimurium in cultured intestinal epithelial cells. J Immunol 1997, 159(11):5550-5559.

67. Neish AS, Gewirtz AT, Zeng H, Young AN, Hobert ME, Karmali V, Rao AS, Madara JL: Prokaryotic regulation of epithelial responses by inhibition of IkappaB-alpha ubiquitination. Science 2000, 289(5484):1560-1563.

68. Barnes PJ, Adcock IM: Glucocorticoid resistance in inflammatory diseases. Lancet 2009, 373(9678):1905-1917.

69. McAuley JL, Linden SK, Png CW, King RM, Pennington HL, Gendler SJ, Florin TH, Hill GR, Korolik V, McGuckin MA: MUC1 cell surface mucin is a critical element of the mucosal barrier to infection. J Clin Invest 2007 117(8):2313-2324.

70. Ray P, Krishnamoorthy N, Ray A: Emerging functions of c-kit and its ligand stem cell factor in dendritic cells: regulators of $\mathrm{T}$ cell differentiation. Cell Cycle 2008, 7(18):2826-2832.

71. Ali S: Role of c-kit/SCF in cause and treatment of gastrointestinal stromal tumors (GIST). Gene 2007, 401(1-2):38-45.

72. Restuccia DF, Hemmings BA: Cell signaling. Blocking Akt-ivity. Science 2009, 325(5944):1083-1084

73. Kim JM, Eckmann L, Savidge TC, Lowe DC, Witthoft T, Kagnoff MF: Apoptosis of human intestinal epithelial cells after bacterial invasion. J Clin Invest 1998, 102(10):1815-1823.

74. Jones RM, Wu H, Wentworth C, Luo L, Collier-Hyams L, Neish AS: Salmonella AvrA Coordinates Suppression of Host Immune and Apoptotic Defenses via JNK Pathway Blockade. Cell Host Microbe 2008, 3(4):233-244.

75. Steele-Mortimer O, Knodler LA, Marcus SL, Scheid MP, Goh B, Pfeifer CG Duronio V, Finlay BB: Activation of Akt/protein kinase B in epithelial cells by the Salmonella typhimurium effector sigD. J Biol Chem 2000, 275(48):37718-37724

76. Knodler LA, Finlay BB, Steele-Mortimer O: The Salmonella effector protein SopB protects epithelial cells from apoptosis by sustained activation of Akt. J Biol Chem 2005, 280(10):9058-9064.

77. Galan JE, Pace J, Hayman MJ: Involvement of the epidermal growth factor receptor in the invasion of cultured mammalian cells by Salmonella typhimurium. Nature 1992, 357(6379):588-589.

78. Oda K, Matsuoka Y, Funahashi A, Kitano H: A comprehensive pathway map of epidermal growth factor receptor signaling. Mol Syst Biol 2005, 1, 20050010

79. Bertelsen LS, Paesold G, Marcus SL, Finlay BB, Eckmann L, Barrett KE: Modulation of chloride secretory responses and barrier function of intestinal epithelial cells by the Salmonella effector protein SigD. Am J Physiol Cell Physiol 2004, 287(4):C939-948.

80. Nilsson R, Bajic VB, Suzuki H, di Bernardo D, Bjorkegren J, Katayama S, Reid JF, Sweet MJ, Gariboldi M, Carninci P, et al: Transcriptional network dynamics in macrophage activation. Genomics 2006, 88(2):133-142.

81. Takaya A, Tomoyasu T, Matsui H, Yamamoto T: The DnaK/DnaJ chaperone machinery of Salmonella enterica serovar Typhimurium is essential for invasion of epithelial cells and survival within macrophages, leading to systemic infection. Infect Immun 2004, 72(3):1364-1373.

82. Bernal-Bayard J, Cardenal-Munoz E, Ramos-Morales F: The Salmonella type III secretion effector, salmonella leucine-rich repeat protein (SIrP), targets the human chaperone ERdj3. J Biol Chem 285(21):16360-16368.
83. Sun SC, Ganchi PA, Ballard DW, Greene WC: NF-kappa B controls expression of inhibitor I kappa B alpha: evidence for an inducible autoregulatory pathway. Science 1993, 259(5103):1912-1915.

84. Totzke G, Essmann F, Pohlmann S, Lindenblatt C, Janicke RU, SchulzeOsthoff K: A novel member of the IkappaB family, human IkappaB-zeta, inhibits transactivation of p65 and its DNA binding. J Biol Chem 2006, 281(18):12645-12654

85. Khan S, Malik F, Suri KA, Singh J: Molecular insight into the immune upregulatory properties of the leaf extract of Ashwagandha and identification of Th1 immunostimulatory chemical entity. Vaccine 2009, 27(43):6080-6087.

86. Bao S, Beagley KW, France MP, Shen J, Husband AJ: Interferon-gamma plays a critical role in intestinal immunity against Salmonella typhimurium infection. Immunology 2000, 99(3):464-472

87. Singh SR, Liu W, Hou SX: The adult Drosophila malpighian tubules are maintained by multipotent stem cells. Cell Stem Cell 2007, 1(2):191-203.

88. Rodenburg W, Bovee-Oudenhoven IM, Kramer E, van der Meer R, Keijer J: Gene expression response of the rat small intestine following oral Salmonella infection. Physiol Genomics 2007, 30(2):123-133.

89. Uthaiah RC, Praefcke GJ, Howard JC, Herrmann C: IIGP1, an interferongamma-inducible 47-kDa GTPase of the mouse, showing cooperative enzymatic activity and GTP-dependent multimerization. J Biol Chem 2003, 278(31):29336-29343

90. Locksley RM, Killeen N, Lenardo MJ: The TNF and TNF receptor superfamilies: integrating mammalian biology. Cell 2001, 104(4):487-501.

91. Gaur U, Aggarwal BB: Regulation of proliferation, survival and apoptosis by members of the TNF superfamily. Biochem Pharmacol 2003, 66(8):1403-1408.

92. Degrandi D, Konermann C, Beuter-Gunia C, Kresse A, Wurthner J, Kurig S, Beer S, Pfeffer K: Extensive characterization of IFN-induced GTPases mGBP1 to mGBP10 involved in host defense. J Immunol 2007, 179(11):7729-7740.

93. Clare S, Goldin R, Hale C, Aspinall R, Simmons C, Mastroeni P, Dougan G: Intracellular adhesion molecule 1 plays a key role in acquired immunity to salmonellosis. Infect Immun 2003, 71(10):5881-5891.

94. Arnold JW, Niesel DW, Annable CR, Hess CB, Asuncion M, Cho YJ, Peterson JW, Klimpel GR: Tumor necrosis factor-alpha mediates the early pathology in Salmonella infection of the gastrointestinal tract. Microb Pathog 1993, 14(3):217-227.

95. Demoulin JB, Renauld JC: Interleukin 9 and its receptor: an overview of structure and function. Int Rev Immunol 1998, 16(3-4):345-364.

96. Levitt RC, McLane MP, MacDonald D, Ferrante V, Weiss C, Zhou T, Holroyd KJ, Nicolaides NC: IL-9 pathway in asthma: new therapeutic targets for allergic inflammatory disorders. J Allergy Clin Immunol 1999 103(5 Pt 2):S485-491

97. Nelms K, Keegan AD, Zamorano J, Ryan JJ, Paul WE: The IL-4 receptor: signaling mechanisms and biologic functions. Annu Rev Immunol 1999, 17:701-738.

98. Polinska B, Matowicka-Karna J, Kemona H: [The cytokines in inflammatory bowel disease]. Postepy Hig Med Dosw (Online) 2009, 63:389-394.

99. Sanchez-Munoz F, Dominguez-Lopez A, Yamamoto-Furusho JK: Role of cytokines in inflammatory bowel disease. World J Gastroenterol 2008, 14(27):4280-4288.

100. Giallourakis C, Kashiwada M, Pan PY, Danial N, Jiang H, Cambier J, Coggeshall KM, Rothman P: Positive regulation of interleukin-4-mediated proliferation by the $\mathrm{SH} 2$-containing inositol-5'-phosphatase. J Biol Chem 2000, 275(38):29275-29282

101. Jiang $H$, Harris MB, Rothman P: IL-4/IL-13 signaling beyond JAK/STAT. Allergy Clin Immunol 2000, 105(6 Pt 1):1063-1070.

102. Knoops L, Renauld JC: IL-9 and its receptor: from signal transduction to tumorigenesis. Growth Factors 2004, 22(4):207-215.

103. Gingras S, Cote S, Simard J: Multiple signal transduction pathways mediate interleukin-4-induced 3beta-hydroxysteroid dehydrogenase/ Delta5-Delta4 isomerase in normal and tumoral target tissues. J Steroid Biochem Mol Biol 2001, 76(1-5):213-225.

104. Wurster AL, Withers DJ, Uchida T, White MF, Grusby MJ: Stat6 and IRS-2 cooperate in interleukin 4 (IL-4)-induced proliferation and differentiation but are dispensable for IL-4-dependent rescue from apoptosis. Mol Cell Biol 2002, 22(1):117-126. 
105. Kroeger KM, Sullivan BM, Locksley RM: IL-18 and IL-33 elicit Th2 cytokines from basophils via a MyD88- and p38alpha-dependent pathway. J Leukoc Biol 2009, 86(4):769-778.

106. Coffman RL: Immunology. The origin of TH2 responses. Science 328(5982):1116-1117.

107. Paul WE, Zhu J: How are $T(H) 2$-type immune responses initiated and amplified? Nat Rev Immunol 10(4):225-235.

108. Agaisse $H$, Perrimon N: The roles of JAK/STAT signaling in Drosophila immune responses. Immunol Rev 2004, 198:72-82.

109. Galiana-Arnoux D, Deddouche S, Imler JL: [Antiviral immunity in drosophila]. J Soc Biol 2007, 201(4):359-365.

110. Cronin SJ, Nehme NT, Limmer S, Liegeois S, Pospisilik JA, Schramek D, Leibbrandt A, Simoes Rde M, Gruber S, Puc U, et al: Genome-wide RNAi screen identifies genes involved in intestinal pathogenic bacterial infection. Science 2009, 325(5938):340-343.

111. Mudter J, Neurath MF: The role of signal transducers and activators of transcription in T inflammatory bowel diseases. Inflamm Bowel Dis 2003, 9(5):332-337.

doi:10.1186/1471-2164-11-722

Cite this article as: Liu et al.: Global analysis of the eukaryotic pathways and networks regulated by Salmonella typhimurium in mouse intestinal infection in vivo. BMC Genomics 2010 11:722.

\section{Submit your next manuscript to BioMed Central} and take full advantage of:

- Convenient online submission

- Thorough peer review

- No space constraints or color figure charges

- Immediate publication on acceptance

- Inclusion in PubMed, CAS, Scopus and Google Scholar

- Research which is freely available for redistribution

Submit your manuscript at www.biomedcentral.com/submit
(Ciomed Central 